San Jose State University

SJSU ScholarWorks

Master's Theses

Master's Theses and Graduate Research

1995

\title{
The stabilization of ribonuclease $A$ against urea by 2'-Cytidine monophosphate
}

Fang Liu

San Jose State University

Follow this and additional works at: https://scholarworks.sjsu.edu/etd_theses

\section{Recommended Citation}

Liu, Fang, "The stabilization of ribonuclease A against urea by 2'-Cytidine monophosphate" (1995). Master's Theses. 1085.

DOI: https://doi.org/10.31979/etd.fvec-q76p

https://scholarworks.sjsu.edu/etd_theses/1085

This Thesis is brought to you for free and open access by the Master's Theses and Graduate Research at SJSU ScholarWorks. It has been accepted for inclusion in Master's Theses by an authorized administrator of SJSU ScholarWorks. For more information, please contact scholarworks@sjsu.edu. 


\section{INFORMATION TO USERS}

This manuscript has been reproduced from the microfilm master. UMI films the text directly from the original or copy submitted. Thus, some thesis and dissertation copies are in typewriter face, while others may be from any type of computer printer.

The quality of this reproduction is dependent upon the quality of the copy submitted. Broken or indistinct print, colored or poor quality illustrations and photographs, print bleedthrough, substandard margins, and improper alignment can adversely affect reproduction.

In the unlikely event that the author did not send UMI a complete mamuscript and there are missing pages, these will be noted. Also, if unauthorized copyright material had to be removed, a note will indicate the deletion.

Oversize materials (e.g., maps, drawings, charts) are reproduced by sectioning the original, beginning at the upper left-hand comer and contimuing from left to right in equal sections with small overlaps. Each original is also photographed in one exposure and is inciuded in reduced form at the back of the book.

Photographs included in the original mamuscript have been reproduced xerographically in this copy. Higher quality $6^{n} \times 9^{n}$ black and white photographic prints are available for any photographs or illustrations appearing in this copy for an additional charge. Contact UMI directly to order.

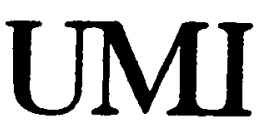

A Bell \& Howell intormation Company

300 North Zeeb Road. Ann Arbor. Mi 48106-1346 USA

$313 ! 761-4700 \quad 800 ; 521-0600$ 


\title{
THE STABILIZATION OF RIBONUCLEASE A AGAINST UREA BY 2'-CYTIDINE MONOPHOSPHATE
}

\author{
A Thesis \\ Presented to \\ The Faculty of the Department of Chemistry \\ San Jose State University \\ In Partial Fulfillment \\ of the Requirements for the Degree \\ Master of Science
}

by

Fang Liu

August, 1995 
OMI Number: 1375709

\section{Copyright 1995 by Liu, Fang \\ All rights reserved.}

UMI Microform 1375709

Copyright 1995, by UMI Company. All rights reserved.

This microform edition is protected against unauthorized copying under Title 17, United states Code.

\section{UMI}

300 North Zeeb Road

Ann Arbor, MI 48103 
(C) 1995

Fang Liu

ALL RIGHTS RESERVED 


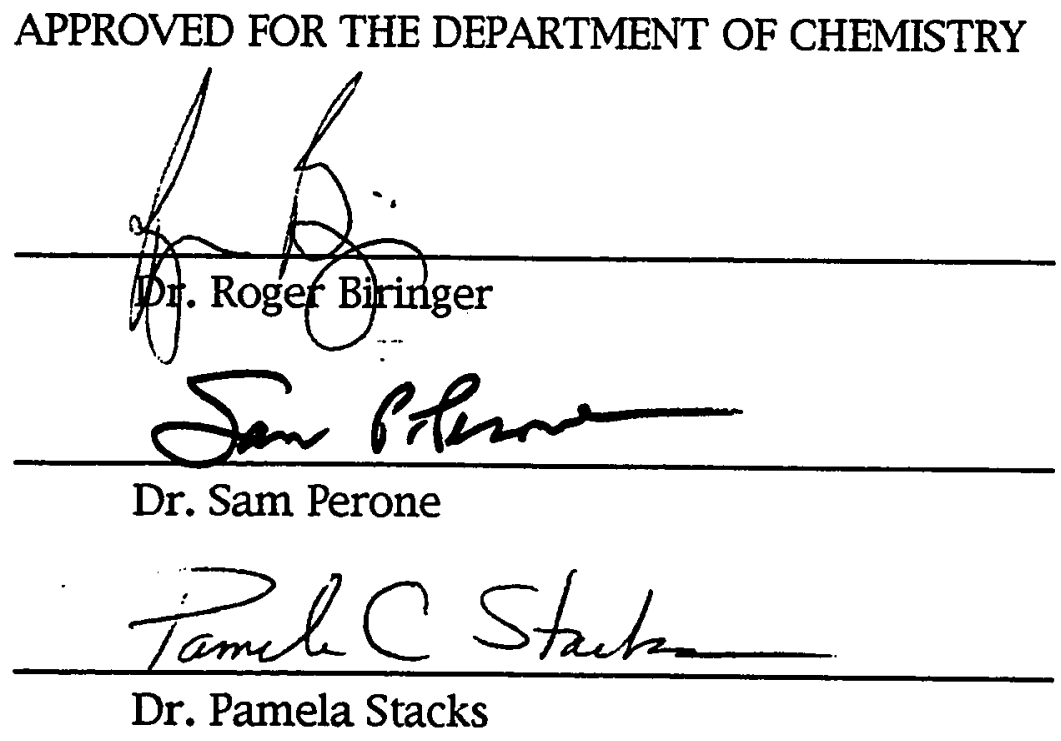

APPROVED FOR THE UNIVERSITY

In. Lou Sewndowati 


\title{
ABSTRACT \\ THE STABILIZATION OF RIBONUCLEASE A AGAINST UREA BY 2'-CYTIDINE MONOPHOSPHATE
}

\author{
by Fang Liu
}

It has been found that a biologically active protein must be accompanied by a specific three-dimensional conformation. This conformation is determined by its primary sequence. However, the mechanism and pathway of how a polypeptide chain leads to the formation of its tertiary structure still remain uncertain.

The reversible unfolding or refolding of a protein is usually achieved by heat, acid, urea, or guanidinium chloride. Although the mechanism and pathway of the unfolding process are not quite clear, it is evident that four types of noncovalent bonds in a protein are partially or fully disrupted.

Cytidine-2'-monophosphate (2'-CMP) is a competitive inhibitor of bovine pancreatic ribonuclease A (RNase A). The knowledge of the effect of 2'-CMP on urea-induced unfolding of RNase A may be helpful in the understanding of the mechanism of urea denaturation. The examination of this effect at $\mathrm{pH} 4$ and $17 \pm 1{ }^{\circ} \mathrm{C}$ by fluorescence and absorbance spectroscopy shows that 2'-CMP stabilizes RNase A against urea-induced unfolding by the binding to the active site of the protein. Hence, the results support the idea that the disruption of the local native conformation at the active site of an enzyme may occur at an early stage in urea-induced denaturation. As an inhibitor with mixed inhibition characteristics and a low binding affinity, 5'CMP has the same effect as 2'-CMP, indicating that the mechanism of the effect is complicated. The data analyzed by both linear and nonlinear least-squares methods also support the existence of an intermediate state in urea-induced unfolding of RNase A. 


\section{ACKNOWLEDGEMENTS}

I wish to express my gratitude to Dr. Biringer for his patient and kind advising on my research and for his careful reading and helpful criticizism of this thesis. I sincerely thank Dr. Perone and Dr. Stacks for their useful suggestions for my thesis. I also thank the instructors for their guidence during my graduate career. 


\section{TABLE OF CONTENTS}

ACKNOWLEDGEMENTS................................................................................ v

TABLE OF CONTENTS....................................................................................... vi

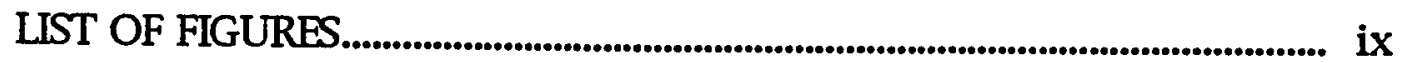

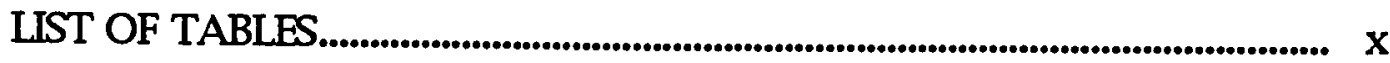

LIST OF ABBREVIATIONS............................................................................

1. INTRODUCTION............................................................................................ 1

1.1 The Structure and the Function of RNase A......................................... 1

1.2 A Question Concerning the Three-Dimensional Conformation and the Biological Function of RNase A.............................................. 6

1.3 The Mechanism and Pathway of Protein Folding............................... 7

1.4 Evidence for the Existence of Intermediate States during Protein Folding in Vitro.............................................................. 7

1.5 Evidence for the Existence of Intermediate States during Protein Unfolding in Vitro.................................................. 11

1.6 The Four Types of Noncovalent Bonds that Stabilize Native and Intermediate Conformations of Proteins.................................... 12

1.7 Solvent and Solute Entropy as a Driving Force for Protein Folding...................................................................................... 13

1.8 Evidence for Destabilization or Stabilization of Proteins by Weakening or Strengthening of Noncovalent Bonds................ 16

1.9 Studies on the Mechanism and Pathway of Protein Unfolding by Urea and Guanidinium Chloride.

1.10 A Classic Two-State Model for Analysis of a Urea or Guanidinium Chloride Denaturation Curve.................................... 22

1.11 Evaluation of Protein Stability by Linear and Nonlinear Extrapolation Methods

1.12 Fluorescence Spectrofluorometer: One of the Tools for Monitoring Protein Unfolding and Refolding........................... 30

1.13 The Significance and Perspectives of Studies on Protein Folding.

1.14 The Purpose and the Significance of this Project............................. 32

1.15 The Model for the Binding of a Competitive Inhibitor 


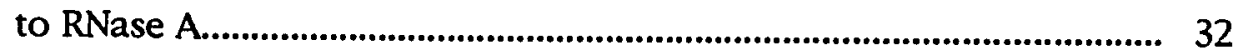

2. MATERIAIS AND METHODS..................................................................... 34

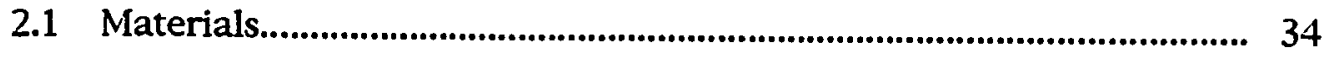

2.2 General Methods.................................................................................. 34

2.3 Fluorescence Properties of RNase A and 2'-CMP........................... 35

2.4 Determination of a Saturation Profile for 2'-CMP and 5'-CMP Binding to RNase A...................................................... 35

2.5 Preparation of the Urea Dilution Series........................................... 36

2.6 Examination of Urea-Induced Denaturation of RNase A in the Absence and Presence of 2'-CMP and 5'-CMP by Fluorescence Spectroscopy.......................................................... 36

2.7 Examination of the Urea-Induced Denaturation of RNase A in the Presence of 2'-CMP by Absorbance Spectroscopy............... 37

2.8 Analysis of the Experimental Data................................................. 37

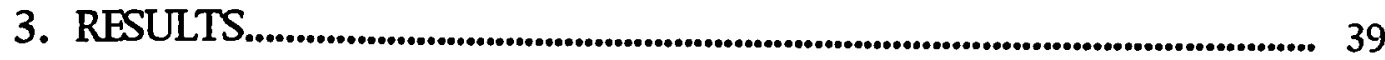

3.1 Examination of the Suitability of Fluorescence Spectroscopy for Application to the Urea-Induced Unfolding of RNase A in the Presence of $100 \mu \mathrm{M} 2^{\prime}-\mathrm{CMP}$

3.2 Urea-Induced Unfolding of RNase $A$ in the Absence of 2'-CMP as Monitored by Fluorescence Spectroscopy.

3.3 Urea-Induced Unfolding of RNase A in the Presence of $100 \mu \mathrm{M}$ 2'-CMP as Monitored by Fluorescence Spectroscopy.

3.4 A Saturation Profile for 2'-CMP Binding to RNase A as Monitored by Absorbance Spectroscopy.

3.5 Urea-Induced Unfolding of RNase $A$ in the Presence of Various Concentrations of 2'-CMP as Monitored by Fluorescence and Absorbance Spectroscopy.

3.6 Determination of a Saturation Profile for 5'-CMP Binding to RNase A

3.7 Urea-Induced Unfolding of RNase A in the Presence of $350 \mu \mathrm{M}$ 5'-CMP as Monitored by Fluorescence Spectroscopy...................... 57

4. DISCUSSION.

4.1 The Quenching of the Intrinsic Fluorescence of RNase A by 2'-CMP.

4.2 The Higher Binding Affinity of 2'-CMP to RNase A at pH 4. 62 
4.3 The Stabilization of RNase $A$ against Urea-Induced Unfolding by 2'-CMP and by 5'-CMP Binding................................................. 64

4.4 The Less-Cooperative Transition in Urea-Induced Unfolding of RNase $A$ in the Absence of 2'-CMP and in the Presence of

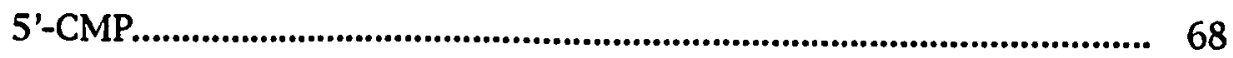

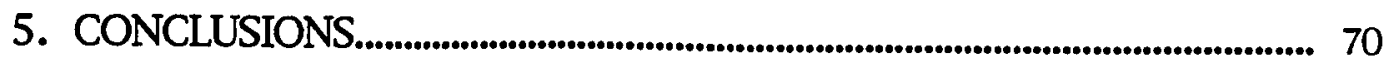

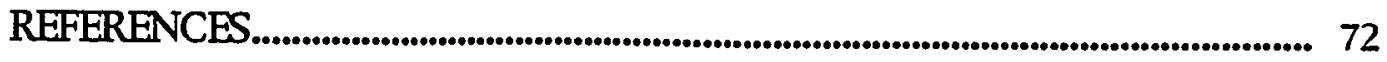




\section{LIST OF FIGURES}

Figure 1: The amino acid sequence for RNase A.......................................... 2

Figure 2: The three-dimensional structure of RNase $A$ in ribbon form..... 3

Figure 3: The catalytic reaction for RNA hydrolysis by KNase A................. 4

Figure 4: The catalytic mechanism for RNA hydrolysis by RNase A.......... 5

Figure 5: Sequential mechanism of protein folding................................... 8

Figure 6: Diagrams for $\alpha$-helical and antiparallel $\beta$-sheet structures....... 14

Figure 7: Hydrogen bond donors and acceptors for several amino acid side chains found in proteins............................................... 15

Figure 8: An example of ion pairs found in proteins................................. 15

Figure 9: Chemical structures for urea and guanidinium chloride........... 21

Figure 10: The linear extrapolation method for a urea-induced protein denaturation curve........................................................................... 23

Figure 11: Linear function of the change in free energy versus urea concentration................................................................................... 26

Figure 12: Schematic drawing of the 3'-CMP-RNase complex as seen from the back of the active site cleft.

Figure 13: Fluorescence spectra for RNase $A$ in the absence and presence of 2'-CMP at pH 4 and $17^{\circ} \mathrm{C}$.

Figure 14: Fluorescence-monitored urea denaturation of RNase $\mathrm{A}$ in the absence and presence of various concentrations of $2^{\prime}-\mathrm{CMP}$ at $\mathrm{pH} 4$ and $17^{\circ} \mathrm{C}$.

Figure 15: Fraction of unfolded representations for the fluorescencemonitored urea denaturation of RNase $\mathrm{A}(31.7 \mu \mathrm{M})$ in the absence and presence of $100 \mu \mathrm{M} 2^{\prime}-\mathrm{CMP}$ at $\mathrm{pH} 4$ and $17^{\circ} \mathrm{C}$

Figure 16: Absorbance spectra for $100 \mu \mathrm{M} 2$ '-CMP in the absence and presence of $31.7 \mu \mathrm{M}$ RNase $\mathrm{A}$ at $\mathrm{pH} 4$ and $17^{\circ} \mathrm{C}$

Figure 17: Saturation profile for 2'-CMP in the presence of $31.7 \mu \mathrm{M}$ RNase $\mathrm{A}$ at $\mathrm{pH} 4$ and $17^{\circ} \mathrm{C}$.

Figure 18: Fraction of unfolded representations for the fluorescencemonitored urea denaturation of RNase $\mathrm{A}(31.7 \mu \mathrm{M})$ in the absence and presence of $200 \mu \mathrm{M} 2^{\prime}-\mathrm{CMP}$ at $\mathrm{pH} 4$ and $17^{\circ} \mathrm{C}$

Figure 19: A)Absorbance spectral difference between native (in $4 \mathrm{M}$ urea) and denatured (in $7 \mathrm{M}$ urea) RNase $\mathrm{A}$ 
B) Absorbance spectral difference for 2'-CMP in the absence and presence of RNase $A$ superimposed on the data from Figure 19A.

Figure 20: A) Urea denaturation data for $\mathrm{RNase} A(31.7 \mu \mathrm{M})$ in the presence of $200 \mu \mathrm{M} 2^{\prime}-\mathrm{CMP}$ at $\mathrm{pH} 4$ and $17^{\circ} \mathrm{C}$.

B) Urea denaturation data for RNase $\mathrm{A}(31.7 \mu \mathrm{M})$ in the presence of $200 \mu \mathrm{M} 2$ '-CMP and the effect of urea on the absorbance of $200 \mu \mathrm{M} 2^{\prime}-\mathrm{CMP}$ in the absence of RNase $\mathrm{A}$ at $\mathrm{pH} 4$ and $17^{\circ} \mathrm{C}$.

Figure 21: A) Saturation profile for 5'-CMP in the presence of $31.7 \mu \mathrm{M}$ RNase $\mathrm{A}$ at $\mathrm{pH} 4$ and $17^{\circ} \mathrm{C}$

B) Semilog representation of the saturation profile for $5^{\prime}$-CMP in the presence of $31.7 \mu \mathrm{M}$ RNase $\mathrm{A}$ at $\mathrm{pH} 4$ and $17^{\circ} \mathrm{C}$

Figure 22: Fraction unfolded representation of the fluorescencemonitored urea denaturation of RNase $A$ in the presence of saturating concentrations of 2'-CMP and 5'-CMP at $\mathrm{pH} 4$ and $17^{\circ} \mathrm{C}$.

\section{LIST OF TABLES}

Table 1: Parameters obtained from urea unfolding of RNase A in the absence and presence of various concentrations of $2^{\prime}-\mathrm{CMP}$ and $350 \mu \mathrm{M} 5^{\prime}-\mathrm{CMP}$ at $\mathrm{pH} 4$ and $17^{\circ} \mathrm{C}$ monitored by fluorescence and absorbance spectroscopy. 


\section{LIST OF ABBREVIATIONS}

RNase A: bovine pancreatic ribonuclease $A$

RNA: ribonucleic acid

2'-CMP: 2'-cytidine monophosphate

3'-CMP: 3'-cytidine monophosphate

5'-CMP: 5'-cytidine monophosphate

GdnCl: guanidinium chloride

NMR: nuclear magnetic resonance

CD: circular dichroism

$\mathrm{K}_{\mathrm{D}}$ : the equilibrium constant for a protein denaturation reaction

$\Delta \mathrm{G}_{\mathrm{H} 2 \mathrm{O}}$ : the free energy change for a protein in the absence of a denaturant

$\mathrm{m}$ : the slope of linear function of free energy change versus denaturant concentration.

$\mathrm{Cm}$ : the transition midpoint in a urea-induced protein denaturation curve An: the solvent exposed surface area in a native protein

Ad: the solvent exposed surface area in a denatured protein 


\section{INTRODUCTION}

It is well established that a biologically active protein must have a particular three-dimensional conformation. This conformation in the functional protein includes a specific secondary ( $\alpha$ helix, $\beta$ pleated sheet, $\beta$ turn, etc.), tertiary, and in some cases, quaternary structure (1). For instance, a specific active pocket in an enzyme, an antigen-binding domain in an immunoglobin, or the heme binding region in hemoglobin requires specific structures. Let us focus on the structure of bovine pancreatic ribonuclease A (RNase A) and its catalytic function.

\subsection{The Structure and the Function of RNase A}

RNase $A$ is one of the most extensively studied proteins. Its structure and function are well understood. RNase A consists of a single polypeptide chain of 124 amino acid residues with four disulfide bonds (Figure 1) (2). This single polypeptide chain is folded mainly into $\beta$-sheet with three short $\alpha$-helices, which are further folded to form the tertiary structure (Figure 2) (3) with a tightly packed hydrophobic core.

The biological function for RNase $A$ is to cleave phosphodiester bonds in ribonucleic acid (RNA) with a preference for pyrimidine nucleotides. Hydrolysis of RNA in the active site of this protein occurs in two steps (Figure 3) (4). In the first step, RNA chain cleavage provides a 2',3'-cyclic phosphate intermediate at the 3'-terminus and new 5'-terminus with a free hydroxyl group. In the second step, the cyclic intermediate is reacted with a water molecule to yield a new 3'-terminus with a free phosphate group. The mechanism of the cleavage of the phosphodiester bond between phosphorus and 5'-oxygen of the ribose ring is shown in Figure 4 (4). In the active center 
Lys-Glu-Thr-Ala-Ala-Ala-Lys-Phe-Gly-Arg-Gln-His-Met-Asp-Ser-Ser-Thr-SerAla-Ala-Ser-Ser-Ser-Asn-Tyr-Cys-Asn-Gln-Met-Met-Lys-Ser-Arg-Asn-Leu20 30

Thr-Lys-Asp-Arg-Cys-Lys-Pro-Val-Asn-Thr-Phe-Val-His-Glu-Ser-Leu-Ala40

Asp-Val-Gln-Ala-Val-Cys-Ser-Gln-Lys-Asn-Val-Ala-Cys-Lys-Asn-Gly-Gln-Thr60

Asn-Cys-Tyr-Gln-Ser-Tyr-Ser-Thr-Met-Ser-Ile-Thr-Asp-Cys-Arg-Glu-Thr-Gly80

Ser-Ser-Lys-Tyr-Pro-Asn-Cys-Ala-Tyr-Lys-Thr-Thr-Gln-Ala-Asn-Lys-His-Ile90 100

Ile-Val-Ala-Cys-Glu-Gly-Asn-Pro-Tyr-Val-Pro-Val-His-Phe-Asp-Ala-Ser-Val110

120

Figure 1: The amino acid sequence for RNase A. Disulfide bonds occur between residues 26 and 84, 40 and 96, 58 and 110, and 65 and 72. (Reproduced with permission from Blackburn, S. Enzyme Structure and Function, Marcel Dekker, 1976, p. 328) 


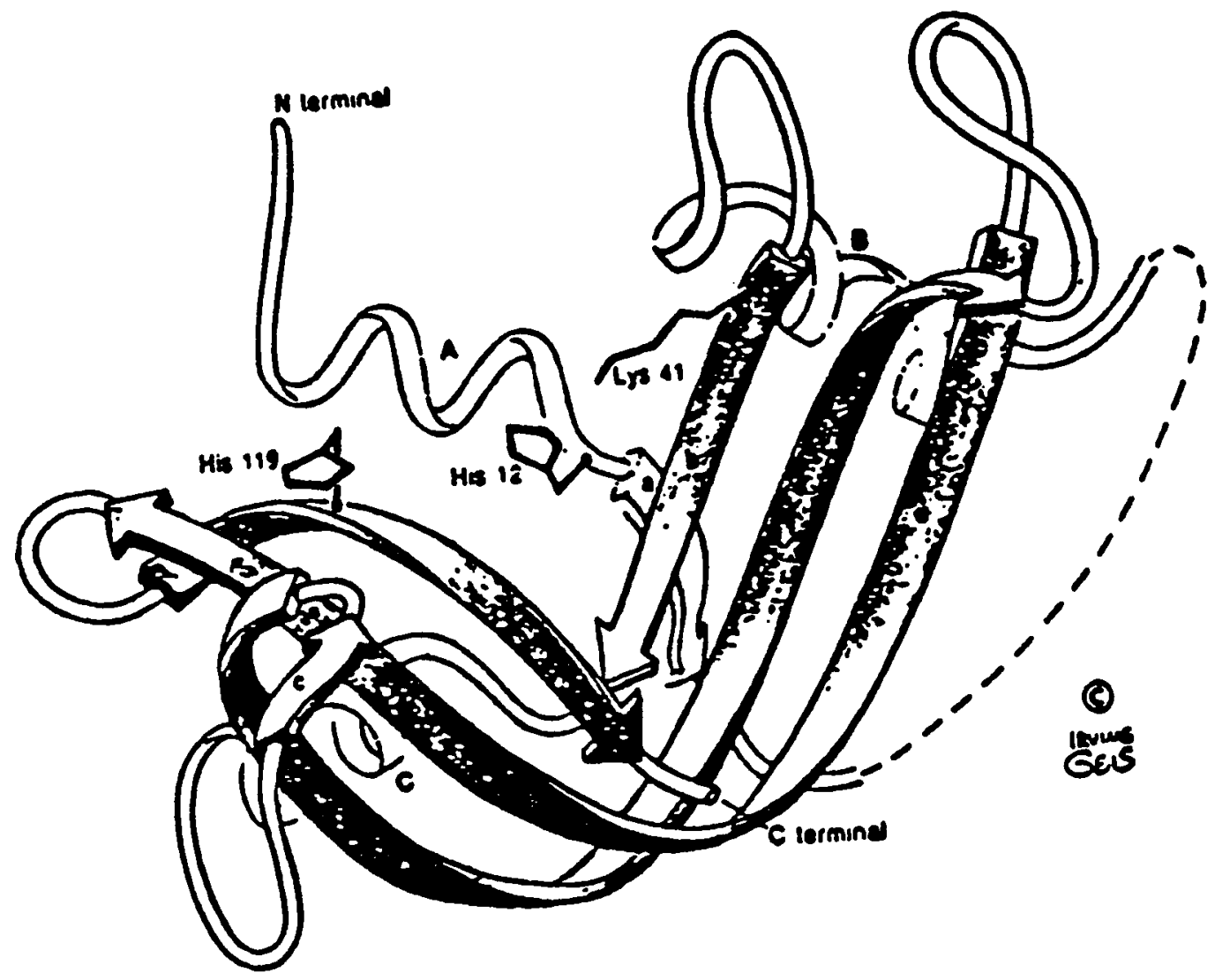

Figure 2: The three-dimensional structure of RNase A in ribbon form. His-12, His-1 19, and Lys-41 in the active site of this enzyme. (Reproduced with permission from Irving Geis in Matthews, C. and van Holde, K. Biochemistry, Benjamin/Cummings, 1990, p. 187) 


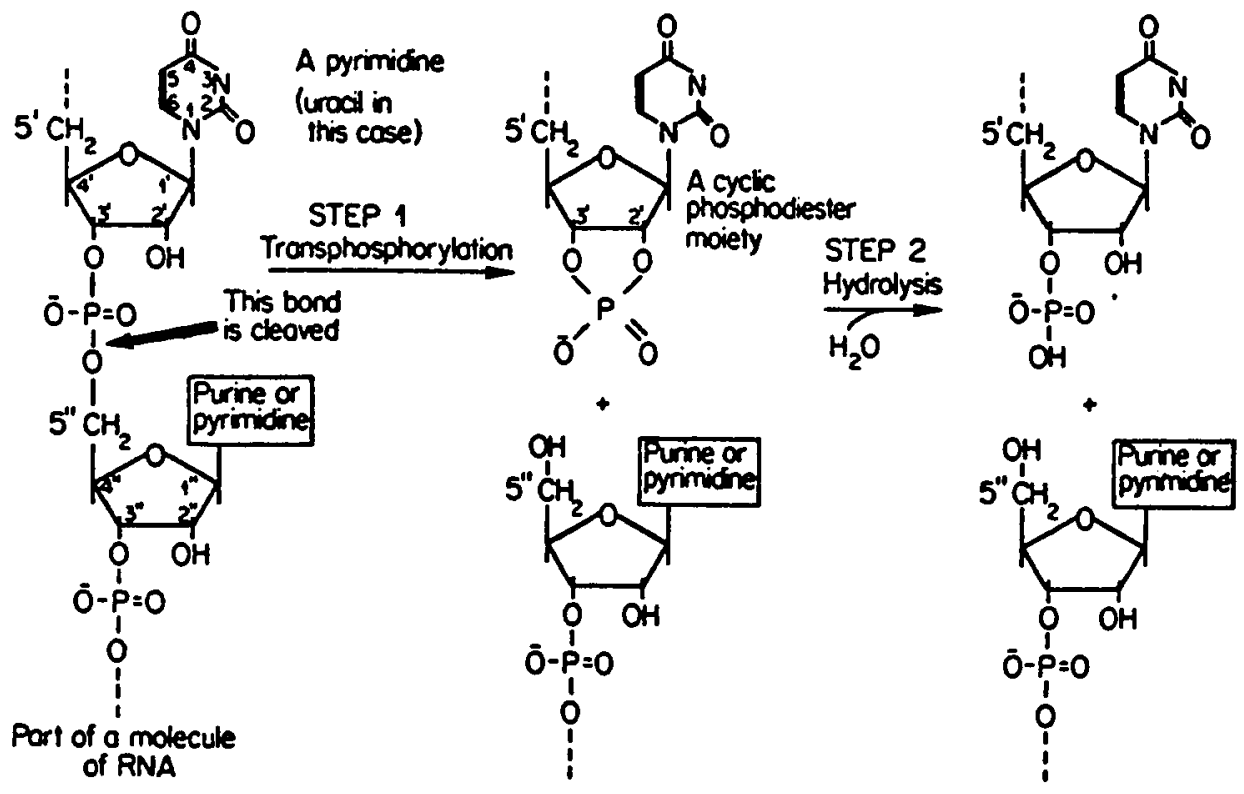

Figure 3: The catalytic reaction for RNA hydrolysis by RNase A. The cleaved phosphodiester bond in RNA is indicated by an arrow. (Reproduced with permission from Ferdinand, W. The Enzyme Molecule, John Wiley and Sons, 1976, p. 131) 


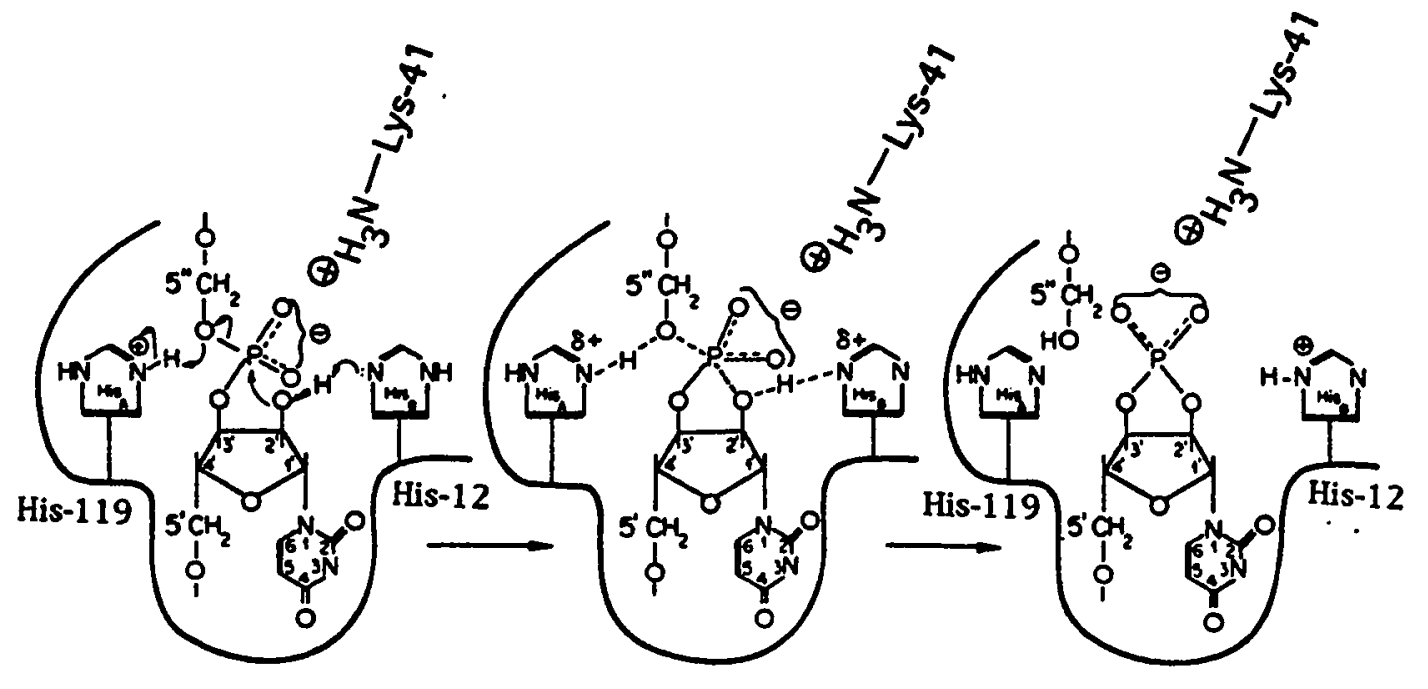

Figure 4: The catalytic mechanism for RNA hydrolysis by RNase A. His-12, His119 , and Lys-41 in the active package of RNase A. (Reproduced with permission from Ferdinand, W. The Enzyme Molecule, John Wiley and Sons, 1976, p. 135) 
of RNase A, His-119 acts as a proton donor and His-12 serves as a proton acceptor in the formation of the 2',3'-cyclic phosphate intermediate. Positively charged Lys-41 stabilizes the negatively charged intermediate through electrostatic interactions. The 2',3'-cyclic intermediate is then hydrolyzed by water via a reversal of the first stage. His-12 acts as the proton donor and His-119 serves as the proton acceptor. Positively charged Lys-41 (perhaps as well as His-119) stabilizes the negatively charged product (nucleoside-3'-phosphate).

\subsection{A Question Concerning the Three-Dimensional Conformation} and the Biological Function of RNase $A$

Examination of Figure 1 reveals that His-12, His-119, and Lys-41 are far apart in the linear sequence, whereas they must be near each other in the active site (Figure 2) in order for RNase A to perform its biological function. These facts raise the question, how do these residues come together (threedimensional conformation) during or after biosynthesis of RNase A (primary structure) on a ribosome?

This question was addressed experimentally by Christian Anfinsen in the 1950's (1). The experiments showed that native RNase A could be denatured and reduced in $8 \mathrm{M}$ urea and $\beta$-mercaptoethanol respectively with the accompanying loss of catalytic activity. He also found that denatured-reduced RNase A could be renatured by the removal of urea, followed by air oxidation. All of the measured activities and properties of the renatured and reoxidized RNase A were identical to those of the native species. These experimental data clearly reveal that: 1) protein unfolding and refolding are completely reversible under certain conditions, and 2) some information that specifies the three-dimensional structure of RNase A must be in the amino acid 
sequence. How is this information encoded and how does it lead an unfolded polypeptide chain to the formation of its three-dimensional conformation?

\subsection{The Mechanism and Pathway of Protein Folding}

At present, a complete answer to above question is not possible since the rules that define the mechanism and pathway of protein folding have not been determined yet, although much effort has been made by many scientists working in the protein folding field. On the basis of numerous experimental evidence and theoretical studies, a number of models have been established for the purpose of describing the possible pathways of the protein folding. However, the transition intermediate model (sequential model) (5) seems to be popular for explaining the folding process (Figure 5). The model assumes that an unfolded polypeptide chain starts folding through the temporary formation of small fragments of fluctuating secondary structure ( $\alpha$ helix or $\beta$ sheet). This transient intermediate is further stabilized by formation of secondary structure complexes between these fragments $(\alpha \alpha, \beta \beta$, or $\alpha \beta)$. This partially folded structure then packs together to give a compact molten globule state which, by local rearrangements, folds to give a native folded state. This model does not completely answer the question because it does not provide the information (or code) that initiates and guides the folding process. However, it provides a clue that recognition of specific intermediate structures may be helpful in the understanding of the mechanism and pathway of protein folding since the intermediates may play an important role in determining how a protein folds.

\subsection{Evidence for the Existence of Intermediate States During Protein Folding in Vitro}




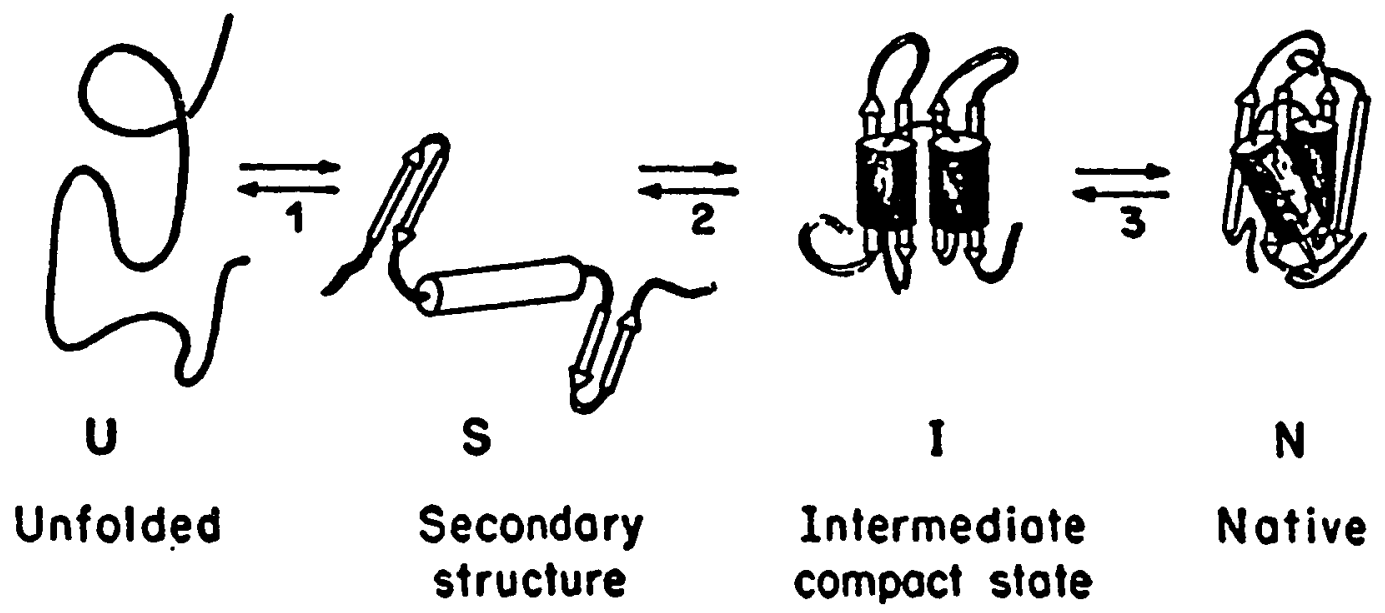

Figure 5: Sequential mechanism of protein folding. (Reproduced with permission from Ptitsyn, O. J. Prot. Chem. 1987, 6, p. 274) U, completely unfolded state (random coil); S, fluctuating secondary structure; I, intermediate globular state; $\mathrm{N}$, native state. 
The experimental data for establishing and supporting the sequential model have shown the existence of partially folded intermediates in protein folding pathway. Such intermediates are difficult to isolate due to their low concentrations and instability (short lifetime). Baldwin and his co-workers have reported that an intermediate formed at an early stage in the refolding of RNase A can be detected either by Fourier transform proton nuclear magnetic resonance (NMR) or by protection of amide protons against exchange $(6,7)$. By examining the imidazole $\mathrm{C}-2$ protons of the four histidine residues (His-12, $-48,-119,-105)$ in RNase A during refolding of thermal-unfolded protein at 10 ${ }^{\circ} \mathrm{C}(\mathrm{pH} 2)$ by NMR, they found a new resonance $(\mathrm{X})$ with a chemical shift that is different from that found in either the native or unfolded RNase A. They interpreted the results to mean that the unfolded protein had been converted into an intermediate in which one histidine residue $(\mathrm{X})$ was in a partially folded state and the other three histidine residues were in an unfolded state. This histidine was shown to be His-12 that is located in the N-terminal helix. In another experiment, they labeled the amide protons of the unfolded protein with ${ }^{3} \mathrm{H}$ and then refolded the protein in $\mathrm{H}_{2} \mathrm{O}$ under conditions where the labeled ${ }^{3} \mathrm{H}$ will be rapidly exchanged out if the protein still remains unfolded. If the labeled protons are protected by protein folding through the formation of a hydrogen-bonded structure, the number of exchangable amide protons will decrease. Baldwin et al. (7) found that during the early stages in the refolding of RNase $A$, the number of exchangable amide protons was higher than those in native state, but lower than those in unfolded state. Hence, they proposed that some amide protons must be protected by the formation of a Hydrogen-bonded structure and thus the structure must be intermediate between the native and unfolded structures.

Similar experimental conclusions were also made by Biringer and Fink (8- 
11). Intermediates in the refolding of RNase A were detected in aqueousmethanol cryosolvents at subzero temperature by using five different probes: proton NMR, nitrotyrosine absorbance, inhibitor binding, catalytic activity, fluorescence and absorbance. Partially folded intermediates were observed through the rapid appearance of new resonances in the proton NMR spectrum. The rate of peak area reduction for the intermediate state and that of peak area increase for the native state were identical, indicating that this intermediate folds directly to the native state. The rates of refolding of modified RNases (nitro-Tyr-73, -76 , and -115) were different, indicating that different regions of the molecule fold at different rates, which is also consistent with partially folded intermediates being formed in the folding pathway. The biphasic return of catalytic activity at $\mathrm{pH} 3$ and the biphasic kinetics of inhibitor binding at both pH 3 and 6 also support the existence of nativelike intermediates along the folding pathway. Interestingly, at least one of the proposed intermediates had inhibitor-binding capacity but lacked catalytic activity. The refolding of RNase A as monitored by the change in absorbance and fluorescence was also considered to support the formation of transient intermediates in the folding of this protein.

Intermediate states are not only formed at an early folded stage $(6,7)$, but also late in folding. Schmid (12) identified a nativelike intermediate (I) in the refolding of RNase A. This intermediate had the capacity for inhibitor (2'CMP) binding and enzymatic activity, but was not completely native as judged by the fluorescence properties.

Thus, at least two intermediate states formed during refolding of RNase A have been characterized. One occurs at an early stage during refolding where His-12 is in a partially folded state and the other three histidines are in an unfolded state. One appears at a later stage and has the capacity for inhibitor 
binding and catalytic activity. Besides RNase A, several other globular proteins have also been shown to have intermediates in their folding. Creighton $(13,14)$ trapped two disulfide intermediates during the folding of bovine pancreatic trypsin inhibitor (BPTI). Beasty and Matthews (15) found an early intermediate with a stable amino domain and an unfolded carboxyl domain in the folding of the $\alpha$-subunit of tryptophan synthase. Sugai and his colleagues (16) showed the existence of a transient folding intermediate in the folding of both $\beta$-lactalbumin and lysozyme. In reversible folding of $\beta$ lactamase I, Goto and Fink (17) found molten globule states (intermediate conformation) with a nativelike secondary structure but a largely disordered tertiary structure. Data for the existence of intermediate(s) formed during protein folding have been summarized by Baldwin (18-21), Kuwajima $(22,23)$ as well as by Creighton (24).

\subsection{Evidence for the Existence of Intermediate States During Protein Unfolding in Vitro}

Intermediates have been detected not only during protein refolding in vitro, but also during protein unfolding in vitro. Matthews et al. (25) applied Fourier transform proton NMR to study the thermal denaturation of ribonuclease $\mathrm{A}$ by examination of the imidazole $\mathrm{C}-2$ proton resonances of the histidine residues. Their results implied that at least two regions of the molecule independently denatured at high temperature at low $\mathrm{pH}$, which supports a multistate denaturation mechanism for RNase A. The same analytical technique was also employed by Benz and Roberts for the study of acid, urea, and guanidinium chloride ( $\mathrm{GdnCl}$ ) denaturation of RNase $\mathrm{A}(26,27)$. They concluded that at least two intermediates were populated in the unfolding process, one with His-12 in an unfolded state and the other with both His-12 
and His-119 in an unfolded state. Howarth (28) used carbon-13 NMR to study the thermal unfolding of RNase A. Intermediate states were also observed on either side of the unfolding transition at low pH. Biringer et al. (29) detected methanol-stabilized intermediates by proton NMR during the thermal unfolding of RNase A in methanol cryosolvents. Proof for the existence of partially folded species was based on the appearance of new His C-2 resonances during the unfolding process, whose chemical shifts were neither nativelike nor like that of the unfolded species. Chignell et al. (30) have shown strong evidence for the existence of intermediate states in the urea denaturation of reduced rabbit muscle phosphorylase $b$ as detected by circular dichroism (CD). Two intermediate states could be clearly distinguished in the denaturation profile. Robson and Pain (31) have used ultraviolet absorption and optical rotation to detect an intermediate state in the reversible unfolding and refolding of penicillinase under both thermal and $\mathrm{GdnCl}$ denaturation conditions. Privalov et al. (32) also found that the denaturation process is not always a simple two-state (native and unfolded state) transition. The results of their calorimetric studies on the thermal denaturation of papain showed that this protein exhibited two independent transitions among three states. Baldwin et al. (33) and Fink et al. (34) have shown that a molten globule intermediate conformation is populated during acid induced unfolding of apomyoglobin as well as for other monomeric proteins.

\subsection{The Four Types of Noncovalent Bonds that Stabilize Native and Intermediate Conformations of Proteins}

Now let us go back to the sequential model (Figure 5). It is clear that the stabilization of appropriate intermediate and native states is a very important aspect for the completion of a protein folding process. The question is how a 
native protein or an intermediate state of a protein maintains its own conformation. In other words, what forces are involved in determining the protein conformation at different folding stages? A native protein's structure is stabilized by hydrogen bonds, the hydrophobic effect, electrostatic interactions, van der Waal forces as well as by disulfide bonds in some cases (1). The hydrogen bond is a major force involved in the formation and stabilization of secondary structures such as alpha helix and beta sheet. These bonds involve the interaction of the $\mathrm{NH}$ and $\mathrm{CO}$ groups of the polypeptide backbone (Figure 6). Hydrogen bonds can also be formed between hydrogen bond donors and acceptors on the side chains of some amino acids (Figure 7). These are important for the formation and stabilization of tertiary structure. The hydrophobic effect involves the process whereby nonpolar amino acid residues in a polypeptide chain are preferably transferred from water to the hydrophobic core of the protein (35). This process will be discussed in detail in the next section. Electrostatic interactions involve the attractive and repulsive forces between net charges. The attractive forces (Figure 8) that are important for protein stability usually occur on the protein surface, because few ion pairs are buried in the protein core. The van der Waals forces involve the interactions between tightly packed hydrocarbon side chains in the hydrophobic core of the protein. In contrast to the four types of noncovalent bonds, disulfide bonds involve covalent interactions between two cysteine residues. Not all proteins contain disulfide bonds, but those that do require them for their stability.

\subsection{Solvent and Solute Entropy as a Driving Force for Protein Folding}

Now let us return to the question that was asked at the beginning of the 
A)

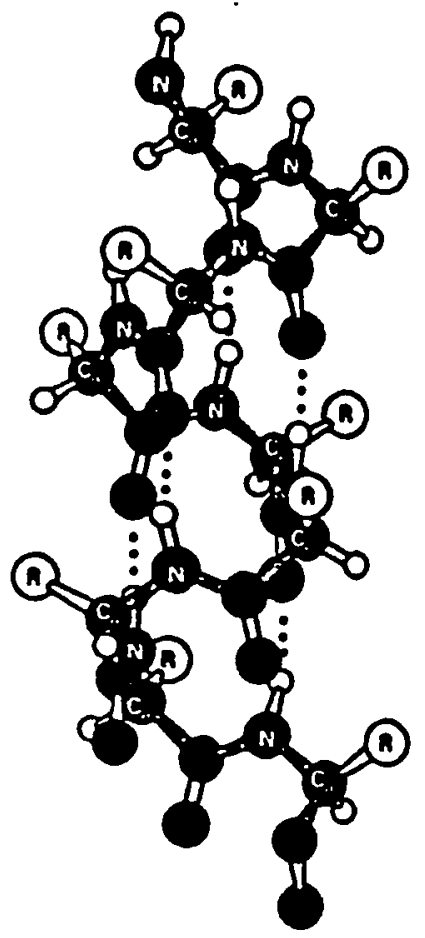

B)

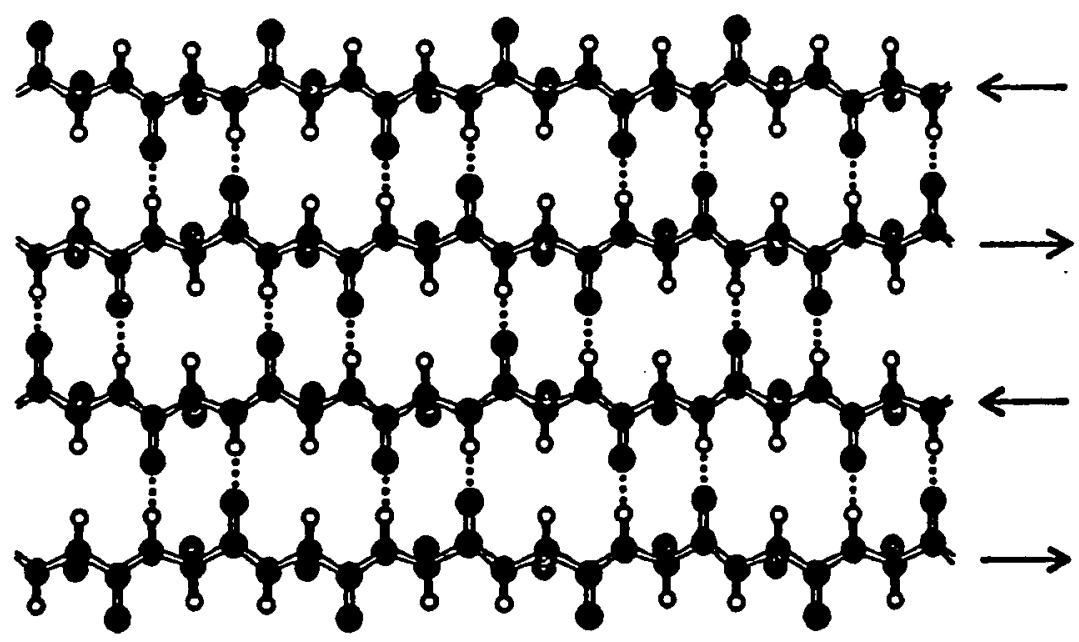

Figure 6: Diagrams for $\alpha$-helical and antiparallel $\beta$-sheet structures. A) $\alpha$ helical structure; B) antiparallel $\beta$-sheet structure. Hydrogen bonds are shown by dots between $\mathrm{NH}$ and $\mathrm{CO}$ groups. (Reproduced with permission from Stryer, L Biochemistry, W. H. Freeman, 1995, p. 29 and p. 31) 
<smiles>Cc1c[nH]c2ccccc12</smiles>

Hydrogen donor group of Trp

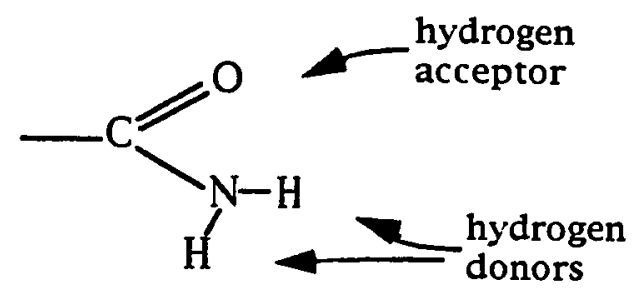

Asn or Gln<smiles>CNC(N)=[NH2+]</smiles>

Hydrogen donor group of Arg
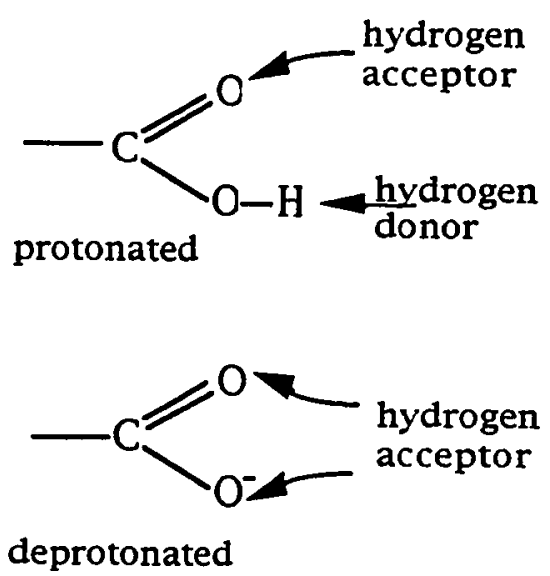

Asp or Glu

Figure 7: Hydrogen bond donors and acceptors for several amino acid side chains found in proteins

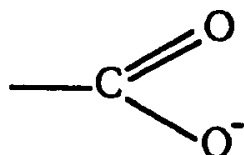

Asp or Glu

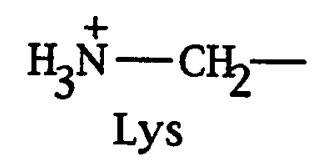

Figure 8: An example of ion pairs found in proteins. 
introduction. What information is encoded in the amino acid sequence and how does it lead an unfolded polypeptide chain to form a particular threedimensional conformation? Renaturation of urea denatured proteins is usually not affected by changes in ionic strength. This suggests that the driving force in protein folding is not electrostatic in nature, as ionic strength has a profound affect on the force of attraction or repulsion between charges (36). However, hydrophobic forces apparently play a significant role. This hypothesis is based on a significant amount of accumulated evidence as outlined in Dill's review (35). At room temperature, when an unfolded polypeptide chain dissolves water, the hydrophobic amino acid residues prefer to interact with each other and minimize their contact with water. Water surrounding any exposed nonpolar residue forms highly ordered clatherate structures in order to accommodate the nonpolar residues and, in doing so, significantly reduce the overall solvent entropy. The natural tendancy towards entropy maximization drives the unfolded polypeptide chain to form a compact tertiary structure in which the nonpolar side chains of residues such as valine, leucine, and phenylalanine, are buried within a hydrophobic core in the center of the globular protein molecule. Thus, solvent entropy causes the collapse of the polypeptide chain and allows for the exposure of the polar and charged side chains on the surface of the protein. Hence, it is reasonable to think that this hydrophobic effect may be the dominant force in protein folding and "other forces are weaker but can affect the protein stability" (35).

\subsection{Evidence for Destabilization or Stabilization of Proteins by Weakening or Strengthening of Noncovalent Bonds}

The four types of noncovalent bonds as well as disulfide bonds determine and maintain the intermediate and native conformation of a protein molecule. 
Any environmental factor that is capable of breaking these forces must contribute to the destabilization of the structure in the native or intermediate conformation of the protein molecule. The power of an environmental factor to destabilize (denature) proteins is based upon its ability to compete with these intramolecular forces.

Singer summarized several studies relating to the alteration of protein conformations by organic cosolvents (37). He found that the hydrophobic cores of RNase A molecules and other proteins were disrupted in pure ethylene glycol. RNase A has six tyrosine residues. Three of them are buried in the protein structure and have "abnormal" pKs. Usually, these residues can not be titrated below pH 12, but Singer observed that they can be titrated in ethylene glycol. This indicates that the hydrophobic solvent molecules disrupt the tertiary structure by interacting with nonpolar side chains of residues in the interior regions of the protein molecules and breaking or weakening the hydrophobic forces required for stabilization of the native conformation of the protein. Singer used CD to show that the helical contents of the protein molecules were not significantly changed when they were transferred from water to ethylene glycol and concluded that the RNase A molecule, in pure ethylene glycol, is in an intermediate conformation in which the helical content of the native form still remains intact, but the hydrophobic region has been disrupted. He also found that the disrupted hydrophobic core of RNase A could be recovered when the protein was removed from ethylene glycol and placed into aqueous solution, indicating that this process is reversible.

Brandts and Hunt (38) examined the effect of ethanol on the thermal denaturation of RNase A. They found that ethanol reduced the thermal stability of the protein. They interpreted the results to mean that ethanol 
serves to enhance the solubility of hydrophobic side chains and thereby promote their exposure to solvent through disruption of the tertiary structure. Similar results have been reported for methanol $(8,9)$ as well as for dimethylsulfoxide and p-dioxane (39).

Both urea and guanidinium ion are strong protein denaturants. The effectiveness of these denaturants is attributed to both hydrogen bonding and hydrophobic interactions (37). These denaturants are thought to effectively compete with intrapeptide hydrogen bonds and, in doing so, disrupt the hydrogen bonds that stabilize both secondary and tertiary structure. Since these denaturants are more hydrophobic than water, they can also disrupt hydrophobic interactions that stabilize the tertiary structure for the reasons noted above for ethanol.

From the results obtained from these aqueous/organic solvent experiments $(37-39)$, it is rationalized that two factors facilitate the disruption of the native configuration of a protein molecule: 1) the formation of the strong hydrogen bonds between the solvent and the protein solute, and 2) enhancement of the solubility of hydrophobic side chains.

Besides organic solvents, inorganic ions can also influence the native conformation of protein. Ginsburg and Carroll (40) found that sulfate ion stabilizes RNase $\mathrm{A}$ against thermal denaturation at low $\mathrm{pH}$ and low ionic strength. This result was interpreted as specific ion binding to a thermostable region of RNase $A$ that stabilizes a thermolabile region in the same molecule. The results from Nelson and Hummel et al. (36) also suggest that the binding of a single anion (phosphate, pyrophosphate, sulfate, etc.) stabilizes the RNase A molecule against urea denaturation. Hirs et al. (41) found that the modification of Lys-41 in RNase A by fluorodinitrobenzene (DNP) causes inactivation of the enzyme activity and a small change in conformation. This 
was considered to be a consequence of the lower basicity of the dinitrophenylated Lys-41 as compared to unmodified Lys-41. Hence, these results imply that positively charged Lys-41 at the active site may be, at least, a part of binding site for negatively charged phosphate group. The binding of phosphate ion to the active site through Lys-41 may be one of the contributions that leads to the stabilization of RNase A against urea denaturation.

Nelson and Hummel (42) found that the catalytic activity of RNase A is decreased about $60 \%$ in $4 \mathrm{M}$ urea. Under the same conditions, however, the tertiary structure remains largely intact. This finding was explained to result from a partial disruption of the native conformation about the active center required for substrate binding or cleavage without greatly altering the whole structure of protein. This finding demonstrated that destabilization of a protein could begin with the disruption of a local conformation, such as the active site, by the breakage of noncovalent bonds. This may represent an early stage in denaturation.

In addition to chemical methods, site-directed mutagenesis can also be used to test the involvement of the four types of noncovalent bonds in stabilizing proteins through the replacement of individual amino acids (24). For instance, to examine hydrophobic effect and van der Waals interactions, buried hydrophobic residues have been replaced with more polar residues and the resulting mutant is usually less stable than the wild-type protein. Replacement of amino acids that participate in hydrogen bonds and electrostatic interactions generally reduces the stability of the mutant as well.

\subsection{Studies on the Mechanism and Pathway of Protein Unfolding by Urea and Guanidinium Chloride}


It has been shown that protein folding and unfolding are completely reversible under particular conditions. Most studies on protein folding are performed in vitro where a native protein first must be unfolded or partially unfolded under denaturing conditions, and then the unfolded or partial unfolded protein is refolded by removing the denaturing environment. Thus, understanding of the protein unfolding process is important in the search for mechanism and pathway of protein folding. Both urea and $\mathrm{GdnCl}$ are frequently used as protein denaturants. The mechanism and pathway of how both denaturants work have been studied for many years. During the 1960's, it was found that at low concentrations of urea, one or two urea molecules bind to the active site of RNase $A$ and competitively inhibit this enzyme. At $4 \mathrm{M}$ urea and above, many urea molecules were found to cooperatively attack the enzyme to give an inactive species (42-44). During the 1980's, it was shown that at low concentrations of $\mathrm{GdnCl}$, the denaturant molecules bind to the active site of the enzyme, but do not competitively inhibit it. Instead, they cause a conformational perturbation, which serves to reduce the catalytic activity (45). These results indicate that the denaturation pathway is denaturant dependent and the mechanism of action is complicated. This differential action is most likely due to their different structures (Figure 9). During the 1990's, it was reported (46) that both urea and $\mathrm{GdnCl}$ bind not only to the folded protein but also to the unfolded protein and the number of binding sites increases during protein unfolding. This indicates that some denaturant binding sites are buried in the native tertiary structure. The data from Privalov's laboratory support the assumption that each binding site in a protein is independent and equivalent and the number of binding sites may be related to the types of amino acid residues in the primary sequence. The data further show that the number of potential urea binding sites in an unfolded 

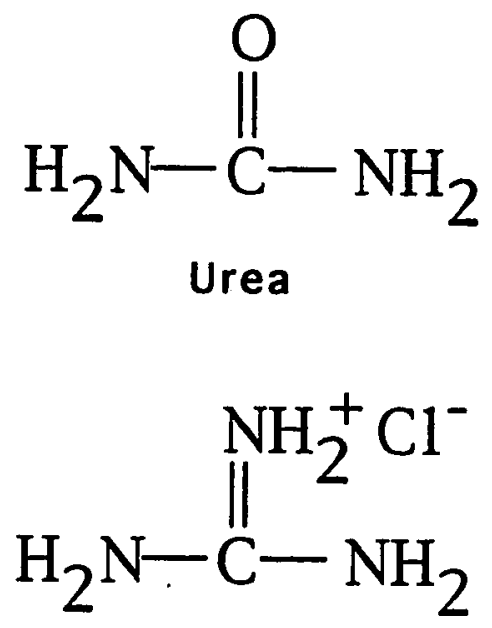

\section{Guanidinium Chloride}

Figure 9: Chemical structures for urea and guanidinium chloride. Urea contains hydrogen donor and acceptor groups. Guanidinium chloride only has hydrogen donor groups with an ion pair. 
polypeptide is larger than the number of $\mathrm{GdnCl}$ binding sites and some potential binding sites still remain empty in the urea-unfolded protein. The data also show that the binding constant for $\mathrm{GdnCl}$ is larger than that for urea and each binding site for either urea or $\mathrm{GdnCl}$ probably involves the formation of several hydrogen bonds between the protein and denaturant molecules.

\subsection{A Classic Two-State Model for Analysis of a Urea or Guanidinium Chloride Denaturation Curve}

Although the precise mechanism and pathway of protein unfolding are not quite clear, urea and $\mathrm{GdnCl}$ denaturation data can usually be analyzed by envoking a two-state model. This model assumes that a protein exists in an equilibrium between the native state $(N)$ and the denatured state (D) and that the concentration of any intermediate is low enough to be neglected $(47,48)$.

$$
\mathrm{N} \Longleftrightarrow \mathrm{D}
$$

The concentration of denatured protein is effectively zero in the absence of a denaturant and increases with increasing concentration of denaturant. Hence, studies on the unfolded states must be carried out in the presence of denaturants. Acid, heat, urea, and $\mathrm{GdnCl}$ are the most frequently used denaturants. As previously indicated, the two-state model assumes that the concentration of intermediate states is low. If the mechanism is complicated by the presence of intermediate, the denaturation curve cannot be analyzed in this way.

A typical denaturation curve (Figure 10A) is composed of three portions: pretransition, transition (the region where the protein unfolds), and 


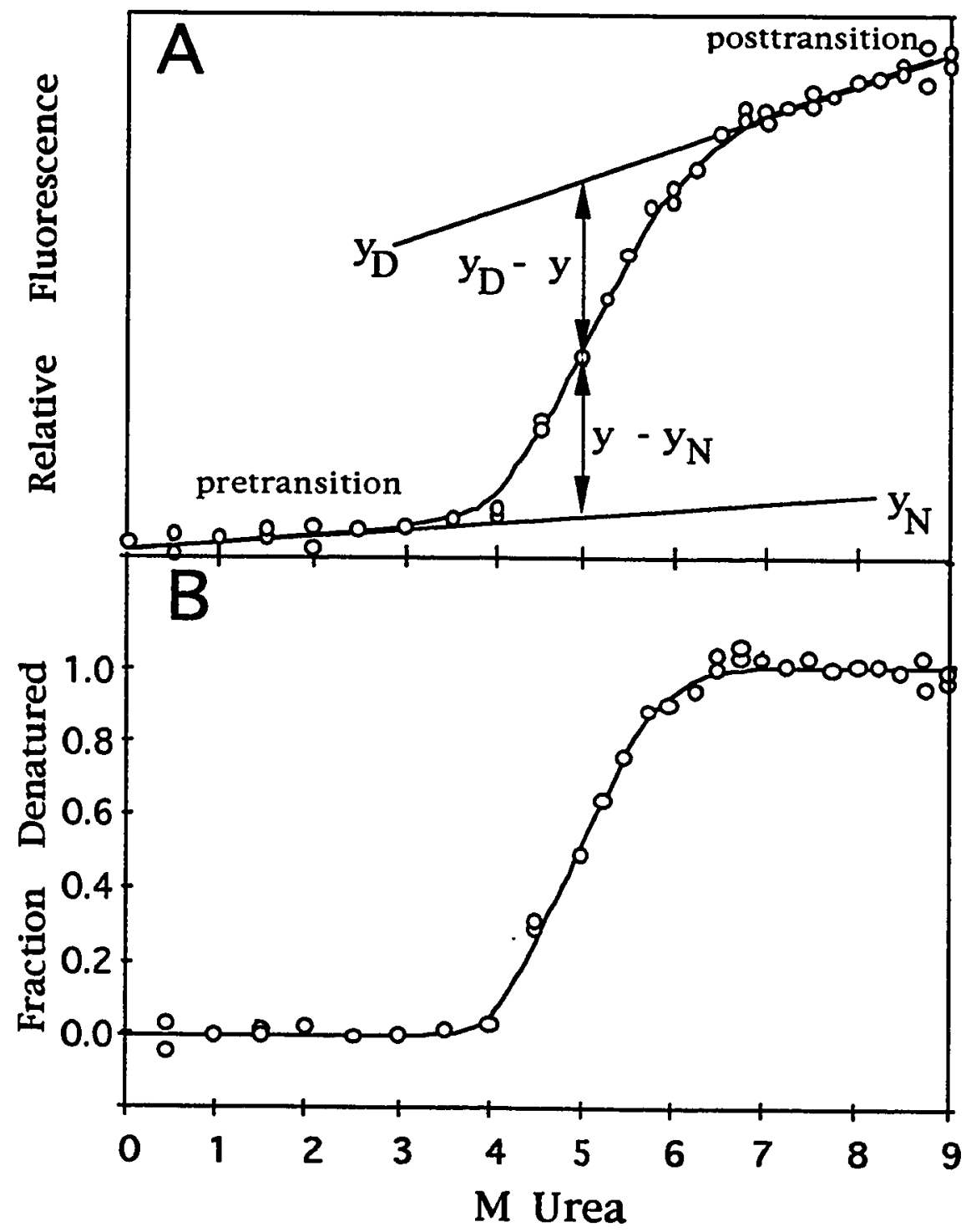

Figure 10: The linear extrapolation method for a urea-induced protein denaturation curve. A) Extrapolation of the linear portions of pretransition and posttransition regions to determine the values for $y-y_{N}$ and $y_{D}-y$ from raw fluorescence data obtained from the urea denaturation of RNase $\mathrm{A}$ at $\mathrm{pH} 4$ and $17{ }^{\circ} \mathrm{C}$ (Biringer, R., unpublished data); B) resulting fraction denatured plot from $A$ where $f_{D}$ (fraction denatured) $=\left(y-y_{N}\right) /\left(y_{D}-y_{N}\right)$. 
posttransition regions. As the concentration of denaturant $(x)$ is increased, any observable parameter $(y)$ that measures protein structure (eg. optical rotation, circular dichriosm, fluorescence or ultraviolet absorbance) changes as the protein unfolds. In order to compare data obtained with different methods, the amplitudes of the signals must be standardized as fraction denatured versus denaturant concentration (Figure 10B). The method most frequently employed assumes that signal changes in both pretransition and posttransition regions reflect a solvent effect on the native and denatured states respectively and that only the transition region contains information about unfolding. Signal values corresponding to the native state $\left(y_{N}\right)$ and the denatured state $\left(y_{D}\right)$ can be easily obtained from the pretransition and posttransition regions, respectively. At any point in the transition region, the signal amplitude is given by

$$
y=f_{N} y_{N}+f_{D} y_{D}
$$

where the values of $y_{N}$ and $y_{D}$ are obtained at each point in the denaturation by extrapolation from the linear portions of pretransition and posttransition regions, and $f_{N}$ and $f_{D}$ represent the fraction of the protein in the native and denatured states, respectively. Since the sum of $f_{N}$ and $f_{D}$ must be unity, then

$$
y=y_{N}+f_{D}\left(y_{D}-y_{N}\right)
$$

and thus

$$
f_{D}=\left(y-y_{N}\right) /\left(y_{D}-y_{N}\right)
$$


Conversion of the data in this manner serves to standardize the signal amplitudes.

Evaluation of the data requires the conversion of $f_{D}$ into units of $\Delta G_{D}$. The equilibrium expression defined in terms of $f_{D}$ is

$$
K_{D}=f_{D} / 1-f_{D}
$$

Since the change in free energy at any point in the transition $\left(\Delta G_{D}\right)$ is related to $\mathrm{K}_{\mathrm{D}}$ by

$$
\Delta \mathrm{G}_{\mathrm{D}}=-\mathrm{RT} \ln \mathrm{K}_{\mathrm{D}}
$$

then

$$
\Delta \mathrm{G}_{\mathrm{D}}=-\mathrm{RT} \ln \left(\mathrm{f}_{\mathrm{D}} / 1-\mathrm{f}_{\mathrm{D}}\right)
$$

Conversion of the data given in Figure 10B yields the plot given in Figure 11. It is generally assumed that $\Delta G_{D}$ is a linear function of denaturant concentration and is defined by

$$
\Delta \mathrm{G}_{\mathrm{D}}=\mathrm{m}(\mathrm{M})+\Delta \mathrm{G}_{\mathrm{H} 2 \mathrm{O}}
$$

where $\mathrm{m}$ is the slope of the line and $\Delta \mathrm{G}_{\mathrm{H} 2 \mathrm{O}}$ is the $\mathrm{y}$ intercept. Evaluation of the data in this manner is known as the linear extrapolation method. Extrapolation of this function to zero concentration of denaturant (Figure 11) will give the value for $\Delta G_{H 2 O}$, which is the free energy change in the absence of denaturant. The error associated with this method has been shown 


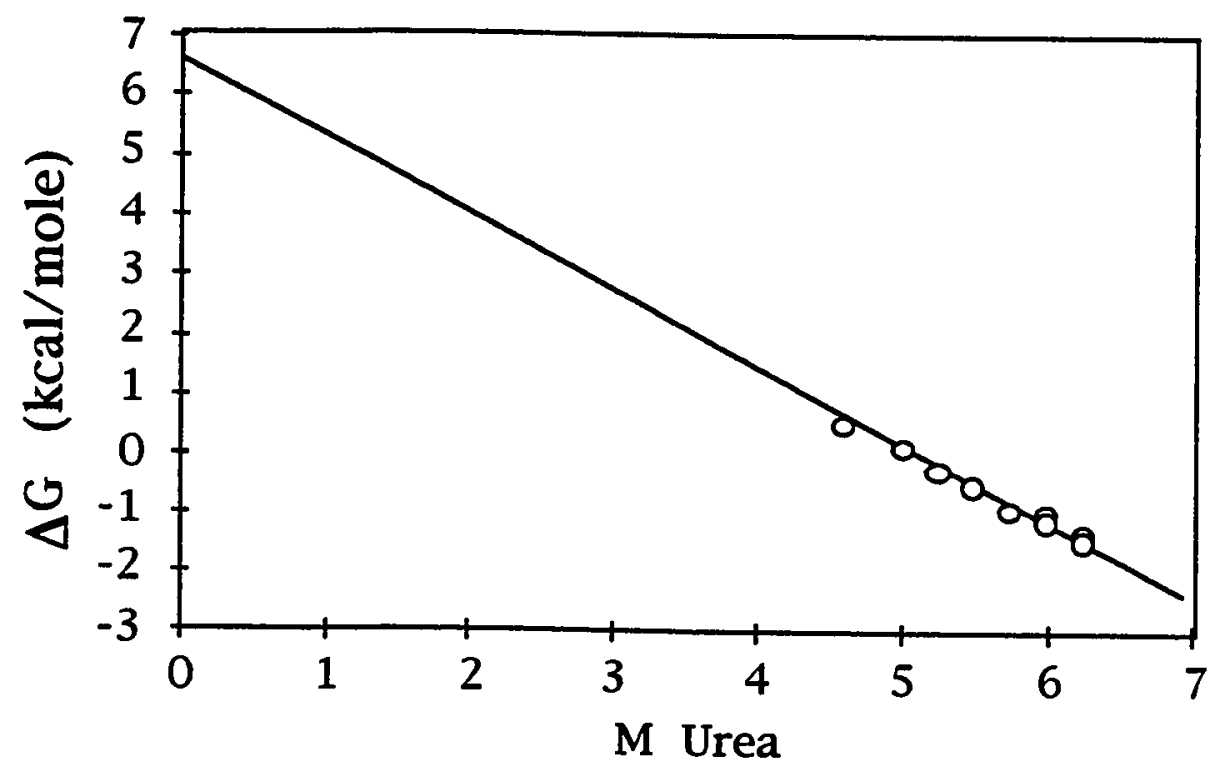

Figure 11: Linear function of the change in free energy versus urea concentration. Data was obtained by analysis of the data in Figure 10B by equation 7 . The slope of the function represents the $m$ value and extrapolation of the line to $0 \mathrm{M}$ urea gives the $\Delta \mathrm{G}_{\mathrm{H} 2 \mathrm{O}}$ value (equation 8 ). 
to be small for urea denaturation studies, but may be significant for other denaturants.

For the two-state model, parameters that define the unfolding transition are $\Delta \mathrm{G}_{\mathrm{H} 2 \mathrm{O}}$, the transition midpoint $(\mathrm{Cm})$, and the " $\mathrm{m}$ " value. The $\mathrm{Cm}$ is the molarity of denaturant required to produce equal amounts of $f_{N}$ and $f_{D}$ and thus where $\Delta G_{D}=0$. Since

$$
\left.\Delta \mathrm{G}_{\mathrm{D}}=\mathrm{m} \text { (denaturant }\right)+\Delta \mathrm{G}_{\mathrm{H} 2 \mathrm{O}}
$$

then

$$
0=m(C m)+\Delta G_{H 2 O}
$$

and

$$
\mathrm{Cm}=-\Delta \mathrm{G}_{\mathrm{H} 2 \mathrm{O}} / \mathrm{m}
$$

The $\mathrm{Cm}$ is the concentration of urea which corresponds to the transition midpoint. It depends on both the stability of the protein in the absence of denaturant $\left(\Delta \mathrm{G}_{\mathrm{H} 2 \mathrm{O}}\right)$ and the value of $\mathrm{m}$, and is most useful for comparison of protein stability under different conditions. The lower the $\mathrm{Cm}$ value, the less stable the protein is under the given conditions. The value for $\mathrm{m}$ is a more direct measure of the effect of denaturant on protein structure. Tanford (49) has shown that the value for $m$ is directly related to the binding of denaturant to the regions of the protein that are newly exposed by the denaturation process. Schellman has proposed (50) that the $\mathrm{m}$ value is directly proportional to the difference in the solvent exposed surface areas of the native state and the denatured state. Since the three parameters are directly related, only two of the three parameters are required to define the unfolding transition. 
Typically, the $\mathrm{Cm}$ and $\mathrm{m}$ values are used for this purpose.

Santoro and Bolen (51) have found that using the linear extrapolation method can lead to the underestimate of the error in the three parameters, since this method only evaluates the data points in the transition region. The linear extrapolation method assumes that no error is associated with either the pretransition or posttransition regions. Instead, they recommend fitting the entire data set to an equation that models the pretransition and posttransition as well as the transition region using nonlinear least-squares methods. Santoro and Bolen have developed the equation given below for this purpose (51).

$y=\left[\left(V^{\circ} N+m_{N}[D]\right)+\left(y_{U}^{\circ}+m_{U}[D]\right) * \exp -\left(\Delta G_{N-U}^{\circ} / R T+m_{G}[D] / R T\right)\right] /\left[1+\exp -\left(\Delta G_{N-U}^{\circ} / R T+m_{G}[D] / R T\right)\right]$

Here, [D] is the denaturant concentration and $y_{N}^{\circ}, y_{U}^{\circ}, m_{N}, m_{U}, m_{G}$, and $\Delta \mathrm{G}^{\circ} \mathrm{N}-\mathrm{U}$ are the fitting parameters. This expression was derived from four equations: 1) $y_{N}=y_{N}^{\circ}+m_{N}[D]$; 2) $y_{U}=y_{U}^{\circ}+m_{U}[D]$; 3) $K_{D}=y_{N}-y / y-y_{D}$; 4) $\Delta G^{\circ}{ }_{N-U}=\Delta G_{D}=-R T \ln K_{D}$. The former two equations represent the extentions of the pretransition and posttransition baselines into the transition region. The latter two equations have been referred to in the discussion of the linear extrapolation method. In addition, $y^{\circ} \mathrm{N}$ and $\mathrm{y}_{U}^{\circ}$ are intercepts, $\mathrm{m}_{\mathrm{N}}$ and $\mathrm{m}_{U}$ are the slopes of the pretransition and posttransition baselines, respectively, and $\Delta G^{\circ}{ }_{N-U}, y, y_{N}, Y_{D}, K_{D}$ have the same meanings described above.

\subsection{Evaluation of Protein Stability by Linear and Nonlinear Extrapolation Methods}

Santoro and Bolen used the nonlinear least-squares method for the determination of the free energy changes of unfolding for 
phenylmethanesulfonyl- $\alpha$-chymotrypsin in $\mathrm{GdnCl}$, urea, and 1,3dimethylurea. They found three identical $\Delta \mathrm{G}_{\mathrm{H} 2 \mathrm{O}}$ values for unfolding of the same protein by the three different denaturants (51), which means that this method is applicable for analysis of the stability of the modified $\alpha$ chymotrypsin no matter what kind of denaturant is used.

Knapp and Pace (52) examined the unfolding of cytochromes $c$ from horse, cow, and Candida krusei by $\mathrm{GdnCl}$ using the linear extrapolation method. By comparison of the values of $\mathrm{Cm}$ and $\Delta \mathrm{G}_{\mathrm{H} 2 \mathrm{O}}$, they concluded that for these homologous proteins, cow is more stable than horse and horse is more stable than Candida. This method has also been used in a comparison of the effectiveness of protein denaturants (53). By comparison of each $\mathrm{m}$ value for the different types of denaturants (the larger the absolute value of $m$, the stronger the denaturant-protein interaction and hence the better the denaturant), Pace and Marshall clearly showed that alkylureas are better denaturants than urea and that the denaturing abilities of alkylureas increase with increasing alkyl chain length. The linear extrapolation method has also been used to examine the stability and denaturation behavior of the wild-type and different mutant forms of staphylococcal nuclease (54). Based on the $m$ values (the larger the $\mathrm{m}$ value, the less stable the protein), Shortle and Meeker determined that some mutants are less stable and some mutants are more stable than wild-type. A more recent study on the $\mathrm{GdnCl}$ denaturation of lysozyme and RNase $A$ in the presence of polyols shows that polyols stabilize protein structures against $\mathrm{GdnCl}$ denaturation, since the $\mathrm{Cm}$ and $\Delta \mathrm{G}_{\mathrm{H} 2 \mathrm{O}}$ are found to increase with increasing concentrations of polyols (55). Pace et al. (56) investigated the conformational stabilities of RNase $\mathrm{A}$ and RNase $\mathrm{T} 1$ as well as other proteins by analysis of urea and $\mathrm{GdnCl}$ denaturation curves through linear and nonlinear least-squares methods. By comparison of $\mathrm{Cm}$ and $\Delta \mathrm{G}_{\mathrm{H} 2 \mathrm{O}}$ 
values, they found that these proteins are less stable at low $\mathrm{pH}$ and high $\mathrm{pH}$ than they are at their isoelectric points.

\subsection{Fluorescence Spectrofluorometer: One of the Tools for Monitoring Protein Unfolding and Refolding}

As mentioned previously, the conformational change in a protein's structure can be monitored by a number of methods. Fluorescence is one of these tools (Figure 10A). Most globular proteins contain either or both tyrosine and tryptophan residues. These aromatic side chains fluoresce and can be monitored with a spectrofluorometer at specific wavelengths.

Typically, the fluorescence is larger for the denatured state. RNase A has six tyrosine residues (Figure 1)(Tyr-25, -73, -76, -92, -97, and -115), three of which are buried (Tyr-25, -92 , and -97 ) in the native structure. There are no tryptophans (57). When these residues are buried in the hydrophobic core of the native protein, the fluorescence emission will be quenched, resulting in a low quantum yield. When they are exposed to the solvent under denaturating conditions, the quenching will be lower and the intrinsic fluorescence will increase. The intensity of this increase is directly proportional to the degree of exposure of the three tyrosines. This technique can be used to measure crude changes in tertiary structure for this and most globular proteins.

\subsection{The Significance and Perspectives of Studies on Protein Folding}

If the code that defines how a polypeptide with a given sequence can lead to the formation of its specific tertiary structure were known, the three dimensional structure could be determined directly from the primary sequence. Armed with this tool, people could create a functional protein by 
genetic engineering even if this protein is not found in nature. One would also know how to maintain a functional protein in a maximally stable state.

This problem has been studied for nearly half a century, yet the knowledge of how a polypeptide chain folds to a functional three-dimensional structure still remains uncertain. Even secondary structure predictions from amino acid sequences are not precise. The predictions based on the allowed values of $\phi$ and $\psi$ angles of the backbone and the frequencies of occurrence of individual amino acids in $\alpha$ helices, $\beta$-sheets, $\beta$-turn (1) give accuracies of only $60 \%$. Several problems that complicate the understanding of protein folding are generalized as follows: First, the protein structure itself is much more complicated and variable. For example, a fragment of amino acid sequence that forms an $\alpha$-helix in one protein may form a $\beta$-sheet in another protein. This implies that a part of the amino acid sequence is not enough to determine secondary structure. On the other hand, some proteins, such as myoglobin and the $\alpha$ and $\beta$ chains of hemoglobin, have different amino acid sequences, but their three-dimensional structures are striking similar (1). How could the different primary structures specify very similar three-dimensional structures? Second, the vitro and vivo folding pathwavs mav be not identical. Although most studies of protein folding are performed in vitro, biological folding processes occur in vivo. Considerable evidence now show that vivo folding may involve additional helper proteins (24). Third, there is a complex interface between chemistry and biology. Creighton (13: p 232) states that: "understanding the chemical basis of the three-dimensional conformations of proteins has not progressed to the same extent, even though the biological properties of proteins generally depend critically upon such a folded conformation." All of these difficulties remain to be overcome. 


\subsection{The Purpose and the Significance of this Project}

The design of this project was based on some previous work by Biringer et al. (unpublished data). The previous work showed that the ability of RNase A to bind cytidine-2'-monophosphate (2'-CMP) in the urea-induced unfolding of this protein is not coincident with the loss of the tertiaty structure for the protein in the absence of 2'-CMP. That is, the fraction-denatured curve for the binding of 2'-CMP to RNase A shifts to higher concentration of urea in comparison to the unfolding curve for RNase $A$ in the absence of 2'-CMP. Possible explanations for these results are as follows: 1) the competitive inhibitor stabilizes the protein against urea denaturation, and 2) partially unfolded protein still maintains its ability to bind 2'-CMP. To determine which of the two possibilities is correct, the urea-induced unfolding of RNase A in the absence and presence of 2'-CMP was examined by fluorescence.

\subsection{The Model for the Binding of a Competitive Inhibitor to RNase} A

Since this project involves the binding of 2'-CMP to RNase A, it is necessary to introduce the model (2) of how a competitive inhibitor binds to RNase A. A competitive inhibitor (3'-CMP or 2'-CMP) is usually bound to the active site of RNase A through the following interactions (Figure 12): Positively charged Lys-41, His-119, and His-12 interact strongly with the negatively charged phosphate group. The side chain of Thr-45 binds to the cytidine ring by a hydrogen bond. The aromatic ring from Phe-120 interacts with the cytidine ring via hydrophobic forces. Both the backbone amide hydrogen from Thr- 45 and the side chain hydroxyl oxygen of Ser-123 are bound to the cytidine via hydrogen bonds. 


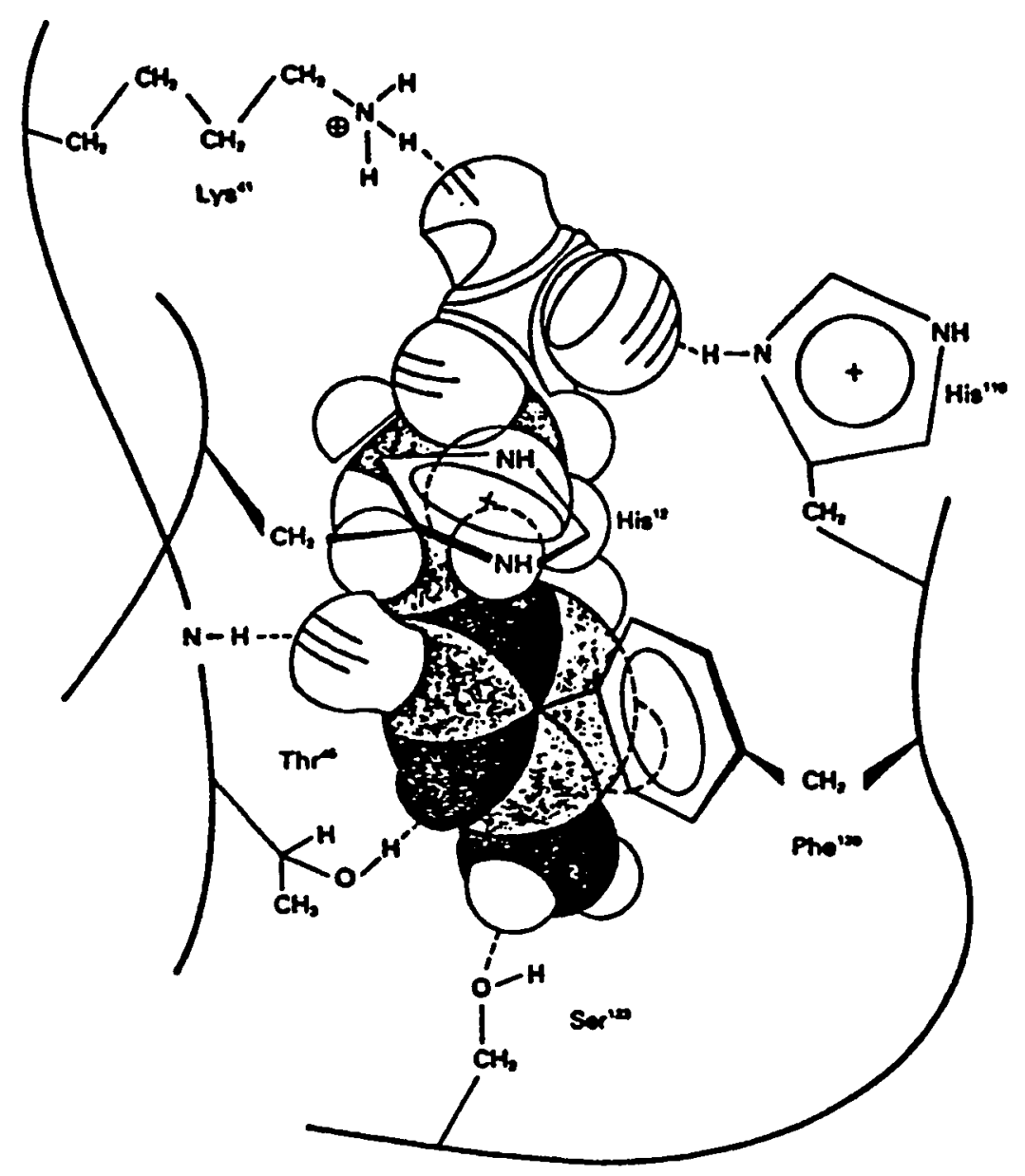

Figure 12: Schematic drawing of the 3'-CMP-RNase complex as seen from the back of the active site cleft. The relative positions of the various amino acid residues in the cleft are indicated. (Reproduced with permission from Blackburn, S. Enzyme Structure and Function, Marcel Dekker, 1976, p. 367) 


\section{MATERIALS AND METHODS}

\subsection{Materials}

Ultrapure urea was purchased from ICN Biochemicals and used without further purification. Deionized-distilled water was employed throughout this study. Bovine pancreatic ribonuclease Type IIIA, sodium 2'-cytidine monophosphate, and disodium 5'-cytidine monophosphate were purchased from Sigma Chemical Company. RNase A was purified further by procedures described previously (Biringer \& Fink, 1988). These procedures facilitate the removal of aggregated RNase and RNase S from RNase A. All other chemicals used were reagent grade.

\subsection{General Methods}

Absorbance measurements were performed with a Hewlett Packard 8452A diode array spectrophotometer and fluorescence measurements were performed with a Perkin Elmer LS-3 spectrofluorometer. Temperature maintenance for all experiments was facilitated by refrigerated circulating baths for which the variability in temperature has been shown to be $\pm 0.1^{\circ} \mathrm{C}$. Insulated thermostatted brass block cell holders were used to maintain the sample temperatures for the spectrophotometric experiments. All solutions were adjusted to a measured $\mathrm{pH}$ of 4.0 and buffered with $0.05 \mathrm{M}$ acetate. Protonic activity measurements (Hwang \& Biringer, unpublished data) of urea containing solutions indicate that the maximum error associated with this procedure is less than $0.2 \mathrm{pH}$ units over the entired range of urea concentrations used in this study. All solutions were filtered through a 0.45 $\mathrm{mm}$ teflon filter before fluorescence and absorbance measurements were made. Protein concentrations were determined spectrophotometrically at 278 
$\mathrm{nm}(9800 \mathrm{AU} / \mathrm{M} \cdot \mathrm{cm}, 0.1 \mathrm{M}$ acetate and $\mathrm{pH} 6)(7)$.

\subsection{Fluorescence Properties of RNase $A$ and 2'-CMP}

To test whether the fluorescence technique could be employed to monitor changes in the tertiary structure of RNase A in the presence of 2'-CMP without interference from the latter, the fluorescence emission spectra for $31.7 \mu \mathrm{M}$ of RNase $A$ in the absence and presence of $100 \mu \mathrm{M}$ 2'-CMP and for $100 \mu \mathrm{M} 2$ '-CMP alone were examined. The fluorescence emissions for these solutions were scanned through a wavelength range from $290 \mathrm{~nm}$ to $400 \mathrm{~nm}$ with excitation at $280 \mathrm{~nm}$ in a $1-\mathrm{cm}$ pathlength quartz cell at $17^{\circ} \mathrm{C}$. The fluorescence emission of a blank consisting of $0.05 \mathrm{M}$ acetate buffer was subtracted from that of all other solutions in order to eliminate any signal produced by acetate buffer.

\subsection{Determination of a Saturation Profile for 2'-CMP and 5'-CMP Binding to RNase A}

A dilution series of 2'-CMP was prepared by mixing appropriate volumes of acetate buffer ( $\mathrm{pH} 4)$ and $536 \mu \mathrm{M}$ 2'-CMP (0.05 M acetate, $\mathrm{pH} 4)$. A 68- $\mu 1$ aliquot of $528 \mu \mathrm{M}$ RNase A stock solution was added to $932 \mu \mathrm{l}$ of various concentrations of 2'-CMP to give a final volume of $1,000 \mu \mathrm{l}$. The final 2'-CMP concentrations ranged from $20 \mu \mathrm{M}$ to $500 \mu \mathrm{M}(20,40,60,80,100,125,150,175,200,250,300,350$, $400,450,500 \mu \mathrm{M})$. Replicates were prepared for each concentration.

Reference blanks were prepared in the same manner with the exception that $68 \mu 1$ of acetate buffer ( $\mathrm{pH} 4$ ) was added instead of the protein stock. The absorbance spectrum for each of the solutions (RNase A + 2'-CMP or 2'-CMP only) was measured at $17{ }^{\circ} \mathrm{C}$ using acetate buffer as a blank, and saved on disk. Difference spectrum for each 2'-CMP concentration was obtained by subtracting the spectrum for 2'-CMP mixed with RNase A from the spectrum 
for 2'-CMP. Baseline offsets, if observed, were corrected by setting the absorbance at $320 \mathrm{~nm}$ to zero. The net absorbance at $294 \mathrm{~nm}$ was plotted against 2'-CMP concentration to yield the saturation profile.

Preparation of a saturation profile for 5'-CMP was the same as described for 2'-CMP with the exception that 5'-CMP was included in each solution rather than 2'-CMP.

\subsection{Preparation of the Urea Dilution Series}

A urea dilution series was prepared by mixing appropriate volumes of acetate buffer and $9.574 \mathrm{M}$ urea stock solution in the absence or in the presence of different concentrations $(53,80,106,213$, and $319 \mu \mathrm{M})$ of 2'-CMP or 5'-CMP $(372 \mu \mathrm{M})$ as necessary. A $150-\mu 1$ aliquot of $528 \mu \mathrm{M}$ RNase A stock solution was added to $2350 \mu 1$ of urea solution to give a final volume of $2500 \mu 1$ and final protein concentration of $31.7 \mu \mathrm{M}$. Urea concentrations from $0 \mathrm{M}$ to 9 $\mathrm{M}$ were prepared in $0.5 \mathrm{M}$ increments for the pretransition region and in 0.25 $M$ increments for the transition and posttransition regions. Final concentrations of 2'-CMP from $50 \mu \mathrm{M}$ to $300 \mu \mathrm{M}(50,75,100,200,300 \mu \mathrm{M})$ and 5'-CMP (350 $\mu \mathrm{M})$ were prepared and examined. Replicates were prepared for each protein sample and relative blanks containing only 2'-CMP or 5'-CMP were prepared as noted above.

\subsection{Examination of Urea-Induced Denaturation of RNase $A$ in the Absence and Presence of 2'-CMP and 5'-CMP by Fluorescence Spectroscopy}

All solutions containing protein were allowed to equilibrate at room temperature for 30 minutes prior to taking any measurement. This allows the protein to unfold to an equilibrium population of molecules. The temperature 
in the sample compartment of fluorometer was adjusted to $17.0 \pm 1^{\circ} \mathrm{C}$. All solutions were precooled in a chilled water bath and then placed into a precooled cuvet and held in the sample chamber. Measurements were taken after thermal-equilibrium to $17{ }^{\circ} \mathrm{C}$ was established. The fluorescence for each sample was plotted versus urea concentration.

\subsection{Examination of the Urea-Induced Denaturation of RNase $A$ in} the Presence of 2'-CMP by Absorbance Spectroscopy

The dilution series that was used for the examination of the urea-induced denaturation of RNase $A$ in the presence of 2'-CMP by fluorescence spectroscopy was also used to examine the unfolding transition by the change in the absorbance of 2'-CMP. Each solution was scanned from $190 \mathrm{~nm}$ to 820 $\mathrm{nm}$ with the solution temperature of $17.0 \pm 1^{\circ} \mathrm{C}$. Temperature maintenance was the same as that used in the fluorescence experiments. Each of the spectra was saved on disk. Duplicate difference spectra were obtained for each concentration of urea by subtracting the spectrum for 2'-CMP mixed with RNase A from the spectrum for only 2'-CMP. The baseline offset for each difference spectrum, if observed, was corrected by setting the absorbance at $350 \mathrm{~nm}$ to zero. The absorbance at $272 \mathrm{~nm}$ from corrected difference spectrum was recorded and reflects the degree of 2'-CMP binding to RNase A in urea. The absorbance at $272 \mathrm{~nm}$ for each difference spectrum was compiled as a function of urea concentration. The effect of urea on the molar absorbance of 2'-CMP was quantitated in the samples containing only 2'-CMP by subtracting the spectrum for $0 \mathrm{M}$ urea from the spectrum for each of the various urea concentrations.

\subsection{Analysis of the Experimental Data}


The data sets for the urea-induced denaturation curves were analyzed by both linear regression (Microsoft Excel) and nonlinear least-squares (NFIT, Island Products) methods referred to in the INTRODUCTION. 


\section{RESULTS}

\subsection{Examination of the Suitability of Fluorescence Spectroscopy for}

Application to the Urea-Induced Unfolding of RNase $A$ in the Presence of $100 \mu \mathrm{M} 2$ '-CMP

The first experiments in this study involved the examination of ureainduced unfolding of RNase $A$ in the absence and presence of 2'-CMP. These were done in order to determine whether the competitive inhibitor can stabilize the protein against urea or whether the partially unfolded protein still maintains its ability to bind 2'-CMP. These experiments require techniques that can independently measure the binding of 2'-CMP and the changes in the tertiary or secondary structure of the protein. Previous experiments have shown that the absorbance at specific wavelengths can be used to measure 2'-CMP binding without interference due to changes in the protein structure. Unfortunately, absorbance spectroscopy can not be used to monitor the protein structure in the presence of 2'-CMP, since the absorbance spectrum for 2'-CMP completely overlaps the entire protein spectrum within the near UV region and any change due to 2'-CMP binding can not be distinguished from changes in protein structure. Besides absorbance, fluorescence can be used to monitor protein structure. If 2'-CMP is not fluorescent, or is weakly fluorescent, or has an emission spectrum different from that for the protein, then fluorescence can be used to monitor changes in the protein structure without interference due to 2'-CMP. To test whether fluorescence could be used, the fluorescence emission spectra were measured for 31.7 $\mu \mathrm{M}$ RNase A, $100 \mu \mathrm{M}$ 2'-CMP, and mixture of $100 \mu \mathrm{M}$ 2'-CMP and $31.7 \mu \mathrm{M}$ RNase A. Figure 13 gives the emission spectra for these solutions. RNase A has the largest fluorescence emission with a wavelength maximum of $305 \mathrm{~nm}$ 


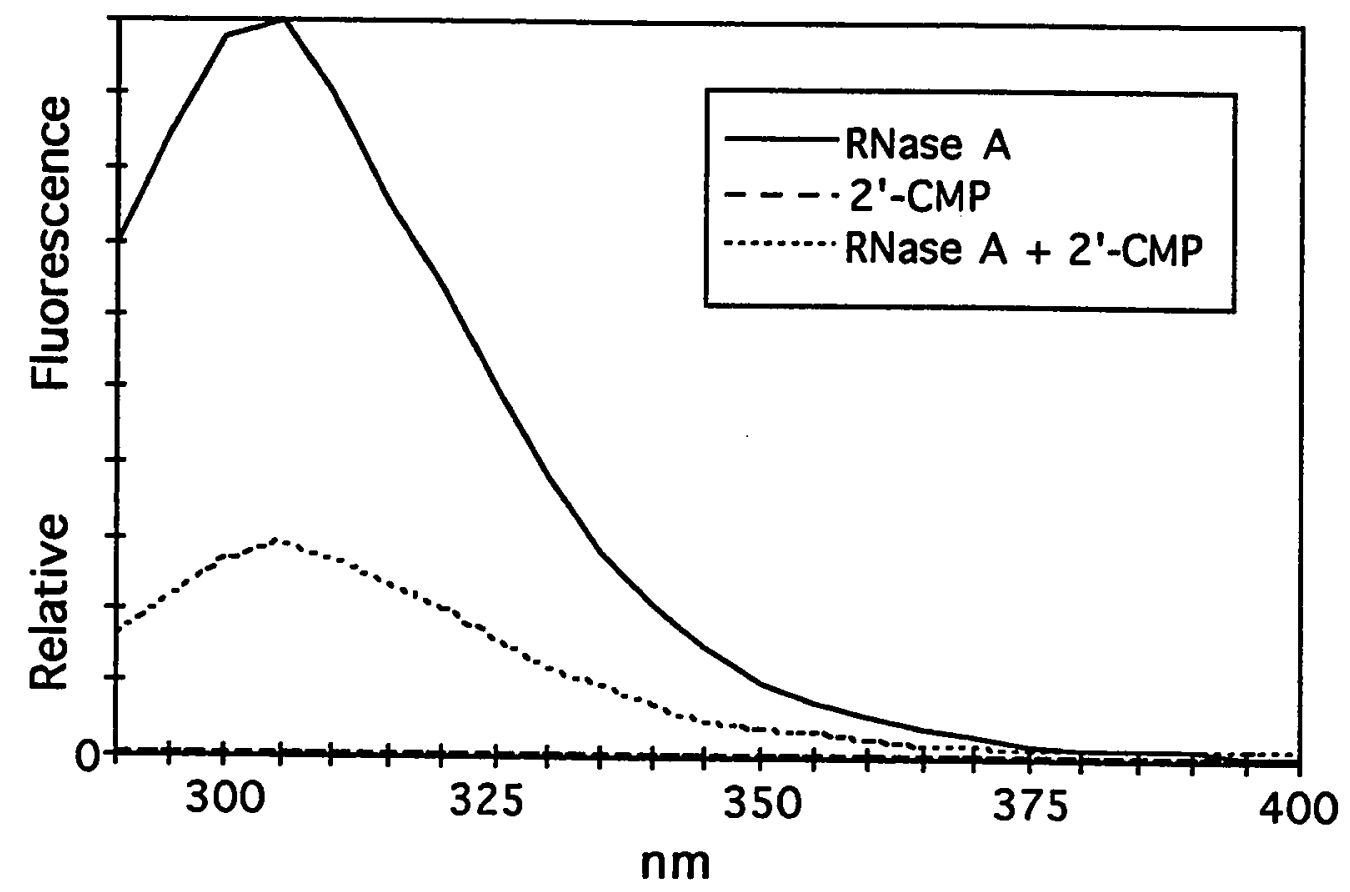

Figure 13: Fluorescence spectra for RNase A in the absence $(-$ ) and presence (….) of 2'-CMP and for 2'-CMP alone (--) at pH $4\left(0.05 \mathrm{M}\right.$ acetate) and $17^{\circ} \mathrm{C}$. RNase A was $31.7 \mu \mathrm{M}$ and 2'-CMP was $100 \mu \mathrm{M}$ in the respective solutions. The excitation wavelength was $280 \mathrm{~nm}$. 
(excitation wavelength at $280 \mathrm{~nm}$ ), whereas 2'-CMP does not show any fluorescence emission in the wavelength range from $290 \mathrm{~nm}$ to $400 \mathrm{~nm}$. This result indicates that fluorescence can be used to monitor any change of the protein structure in the presence of 2'-CMP, since 2'-CMP does not produce a fluorescence signal. However, in the emission spectrum of the solution containing both RNase A and 2'-CMP, one can see that the inhibitor greatly quenches the fluorescence emission of the protein with about a threefold decrease of the intensity. This quenching is observed in all of the denaturation profiles (Figure 14).

\subsection{Urea-Induced Unfolding of RNase $A$ in the Absence of 2'-CMP as Monitored by Fluorescence Spectroscopy}

To investigate the effect of 2'-CMP in the urea-induced unfolding of RNase $A$, one must examine the urea-induced unfolding of RNase $A$ in the absence of 2'-CMP for comparison. This experiment was monitored by the fluorescence emission changes at $305 \mathrm{~nm}$. The changes in the fluorescence at this wavelength serve to measure the exposure of the buried tyrosine residues that accompany denaturation. Figure 15 shows typical unfolding curves. The signal is fairly constant at urea concentrations below $4 \mathrm{M}$, which means that RNase $A$ is native up to this concentration of urea. The fluorescence intensity significantly increases at and after $4.5 \mathrm{M}$ urea, indicating that the unfolding begins at this concentration. The fluorescence is relatively constant after $7 \mathrm{M}$ urea, which implies that the unfolding of the tertiary structure of this protein is complete at this concentration. The data (Figure 15) was fitted to the Santoro-Bolen equation and also evaluated by the linear extrapolation method. The transition midpoint $(\mathrm{Cm})$ of the curve without 2'-CMP was found to be 5.0, which is identical to that obtained from previous results ( $R$. Biringer, 


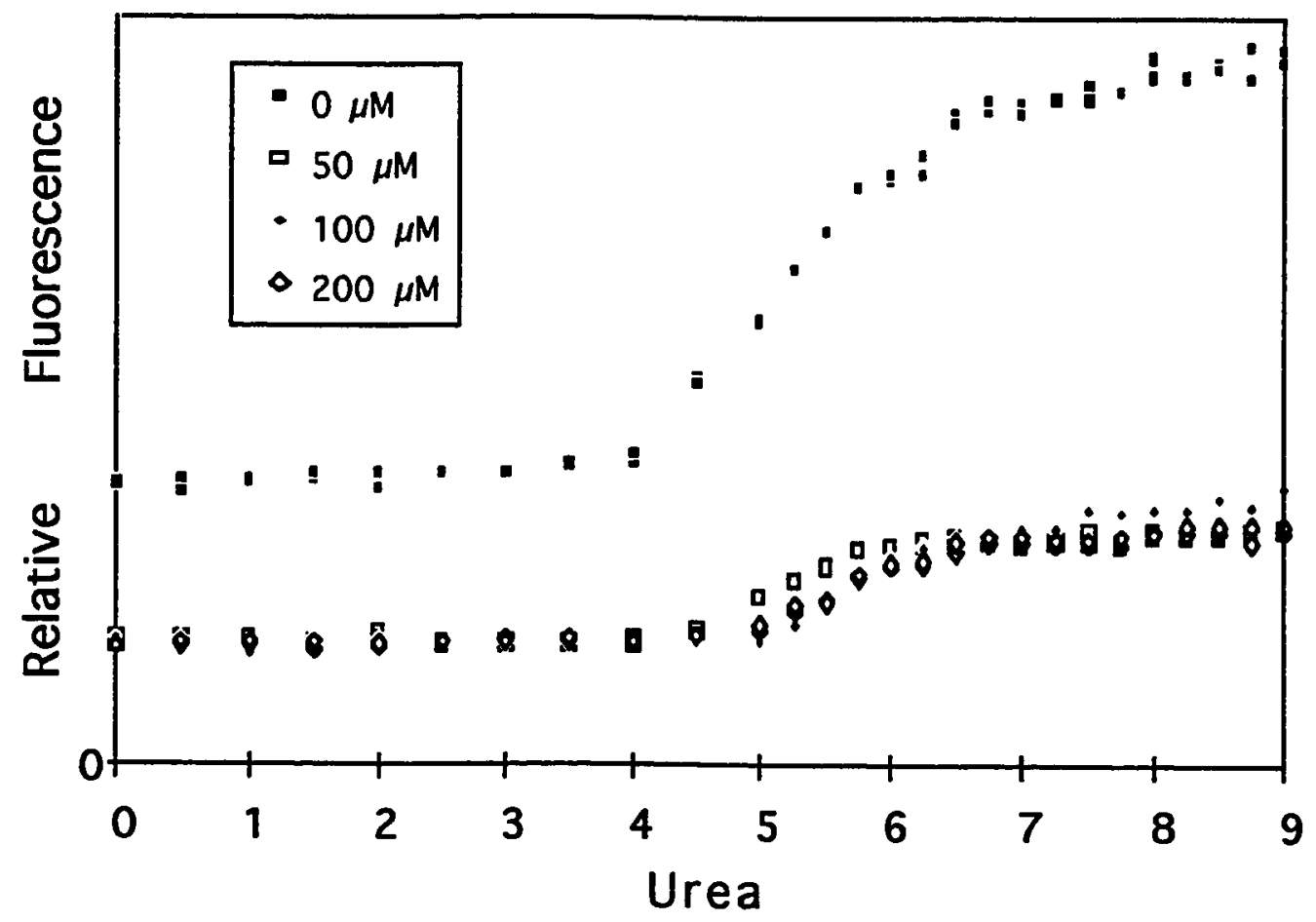

Figure 14: Fluorescence-monitored urea denaturation of RNase $A$ in the absence and presence of various concentrations of 2'-CMP ( $50 \mu \mathrm{M}, 100 \mu \mathrm{M}$, and $200 \mu \mathrm{M})$ at $\mathrm{pH} 4$ and $17^{\circ} \mathrm{C}$. The data gives the relative fluorescence at $305 \mathrm{~nm}$ using $280 \mathrm{~nm}$ excitation. RNase A was $31.7 \mu \mathrm{M}$ in all cases. The legend indicates the concentrations of 2'-CMP used. 


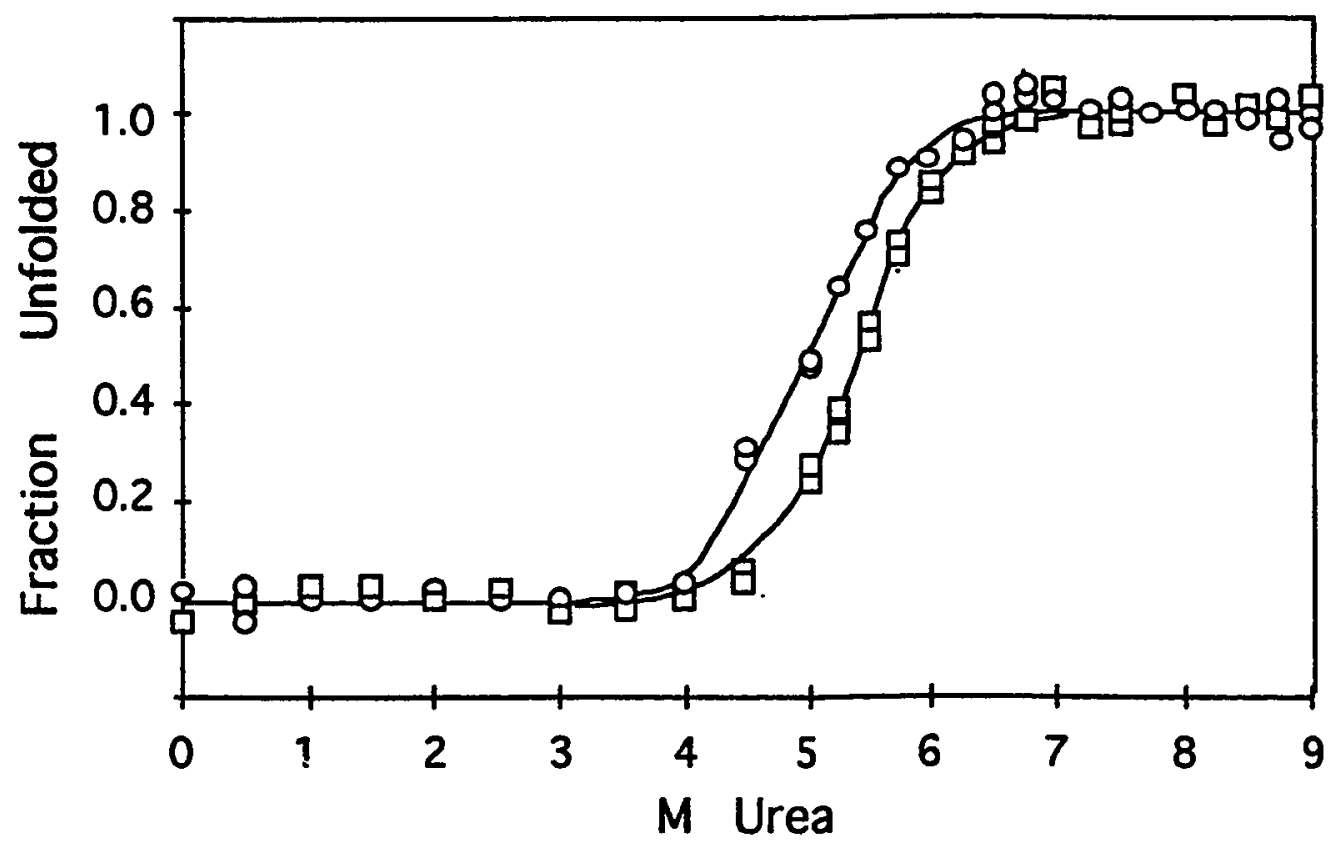

Figure 15: Fraction of unfolded (fraction denatured) representations for the fluorescence-monitored urea denaturation of RNase $\mathrm{A}(31.7 \mu \mathrm{M})$ in the absence (O) and presence $(\square)$ of $100 \mu \mathrm{M} 2^{\prime}-\mathrm{CMP}$ at $\mathrm{pH} 4$ and $17^{\circ} \mathrm{C}$. The curves drawn through the data have no statistical meaning. 
unpublished data).

\subsection{Urea-Induced Unfolding of RNase $A$ in the Presence of $100 \mu \mathrm{M}$ of 2'-CMP as Monitored by Fluorescence Spectroscopy}

To test whether 2'-CMP stabilizes RNase A against urea-induced denaturation, an initial experiment was carried out under the above conditions except in the presence of $100 \mu \mathrm{M}$ 2'-CMP (Figure 15). The reason why $100 \mu \mathrm{M}$ of 2'-CMP was selected as the first tested concentration is because at this concentration, the binding of 2'-CMP to RNase A is close to saturation (10). Hence, one would expect to observe a maximal change of $\mathrm{Cm}$ value under these conditions. If 2'-CMP stabilizes RNase A against urea-induced unfolding, the unfolding curve should shift to higher urea concentrations. If 2'-CMP does not stabilize the protein, the unfolding curve should be the same as that in the absence of 2'-CMP. From Figure 15, it is apparent that the unfolding curve measured in the presence of $100 \mu \mathrm{M}$ 2'-CMP is shifted to a higher concentration of urea as compared to that measured in the absence of 2'-CMP. This implies that 2'-CMP stabilizes RNase A against urea denaturation.

\subsection{A Saturation Profile for 2'-CMP Binding to RNase A as Monitored by Absorbance Spectroscopy}

The initial data show that 2'-CMP stabilizes RNase A against urea denaturation. If the stabilization is related to specific binding of the inhibitor to the active site, then the degree of stabilization should follow the saturation profile for 2'-CMP. That is, the increase of the Cms should follow the increase in 2'-CMP binding with concentration up to saturation, and then the Cms should be independent of increasing 2'-CMP concentrations at and after saturation. If some other effect is responsible, then the degree of stabilization 
will not follow the saturation curve. In order to test this, the urea-induced unfolding of RNase $A$ in the presence of different concentrations of 2'-CMP was examined. In order to determine which 2'-CMP concentrations should be studied, the saturation profile for 2'-CMP binding to RNase A was determined.

The binding of 2'-CMP to RNase A was measured at $294 \mathrm{~nm}$. Three requirements were considered in selecting this wavelength. First, the change of absorbance must reflect the binding of 2'-CMP to RNase A, second, the absorbance must obey Beer's law throughout the concentration range employed, and third, the signal associated with binding must be large. The absorbance spectrum for $100 \mu \mathrm{M}$ 2'-CMP alone, the spectrum for $100 \mu \mathrm{M}$ 2'-CMP with $31.7 \mu \mathrm{M}$ RNase $\mathrm{A}$, and the difference between these are given in Figure 16. One can see that a difference in absorbance that represents the binding complex is found in the $240-310 \mathrm{~nm}$ range. Since the inhibitor concentrations from $20 \mu \mathrm{M}$ to $500 \mu \mathrm{M}$ must be examined, a wavelength must be chosen such that the absorbance for the $500 \mu \mathrm{M}$ solution follows Beer's law. Examination of the 2'-CMP spectra revealed that the absorbance change at $294 \mathrm{~nm}$ provides the largest signal that follows Beer's law.

The amplitude of the difference spectra at $294 \mathrm{~nm}$ for the binding of 2'-CMP to RNase $A$ at a series of concentrations of the competitive inhibitor (20-350 $\mu \mathrm{M})$ is shown in Figure 17. The absorbance difference increases with increasing inhibitor concentrations below $100 \mu \mathrm{M}$, and above $100 \mu \mathrm{M} 2$ '-CMP, the absorbance change is independent of the inhibitor concentrations.

This result indicates that $100 \mu \mathrm{M} 2$ '-CMP is the minimum concentration necessary for RNase A saturation at $\mathrm{pH} 4.0$ and $17^{\circ} \mathrm{C}$. Among the various concentrations of 2'-CMP shown in this plot, four of them were chosen for the next experiment, the urea-induced unfolding of RNase $A$ in the presence of different concentrations of 2'-CMP. Two of these concentrations are lower 


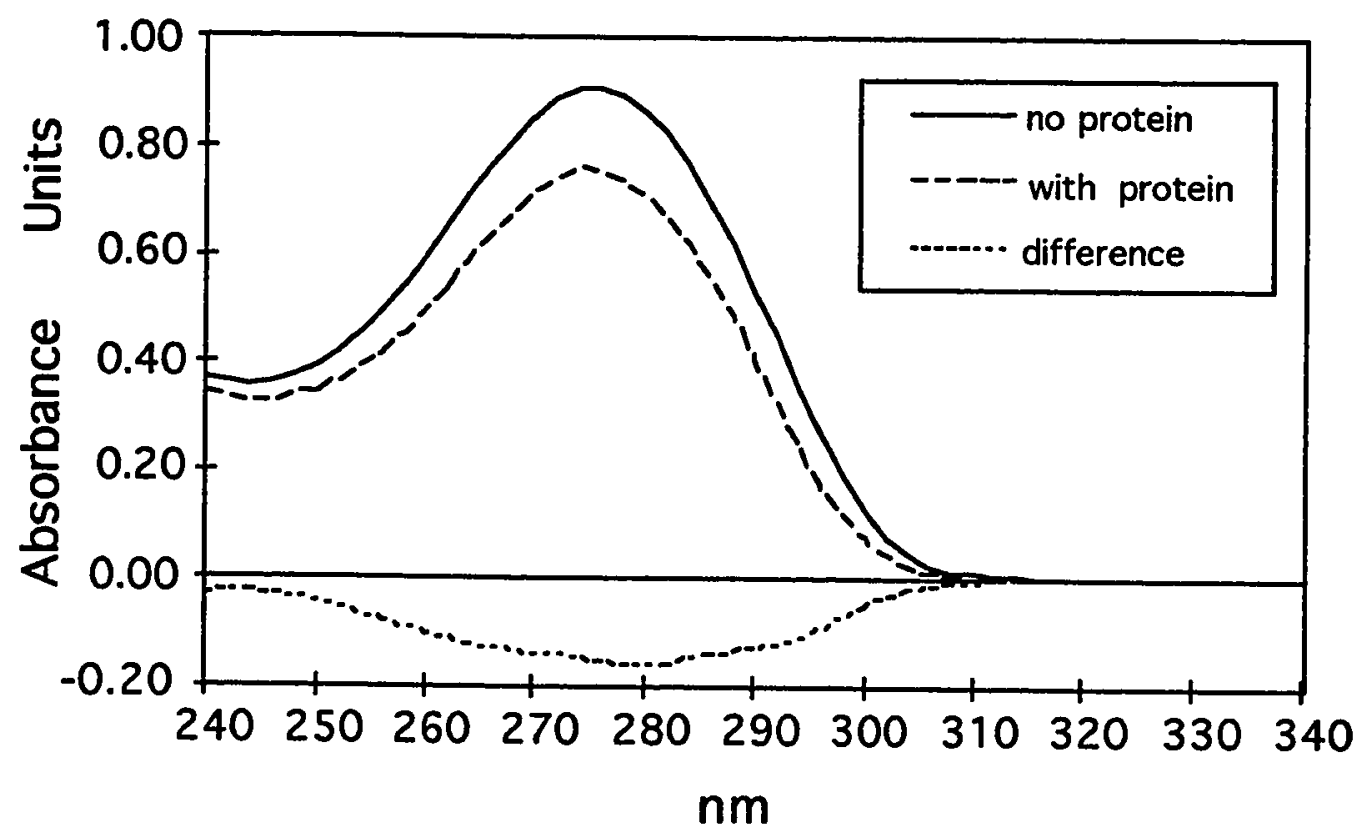

Figure 16: Absorbance spectra for $100 \mu \mathrm{M} 2^{\prime}-\mathrm{CMP}$ in the absence $(-)$ and presence (---) of $31.7 \mu \mathrm{M}$ RNase $\mathrm{A}$ at $\mathrm{pH} 4$ and $17^{\circ} \mathrm{C}$. The 2'-CMP spectrum was subtracted from the spectrum for the mixed solution of 2'-CMP and RNase A to give the difference spectrum (......). 


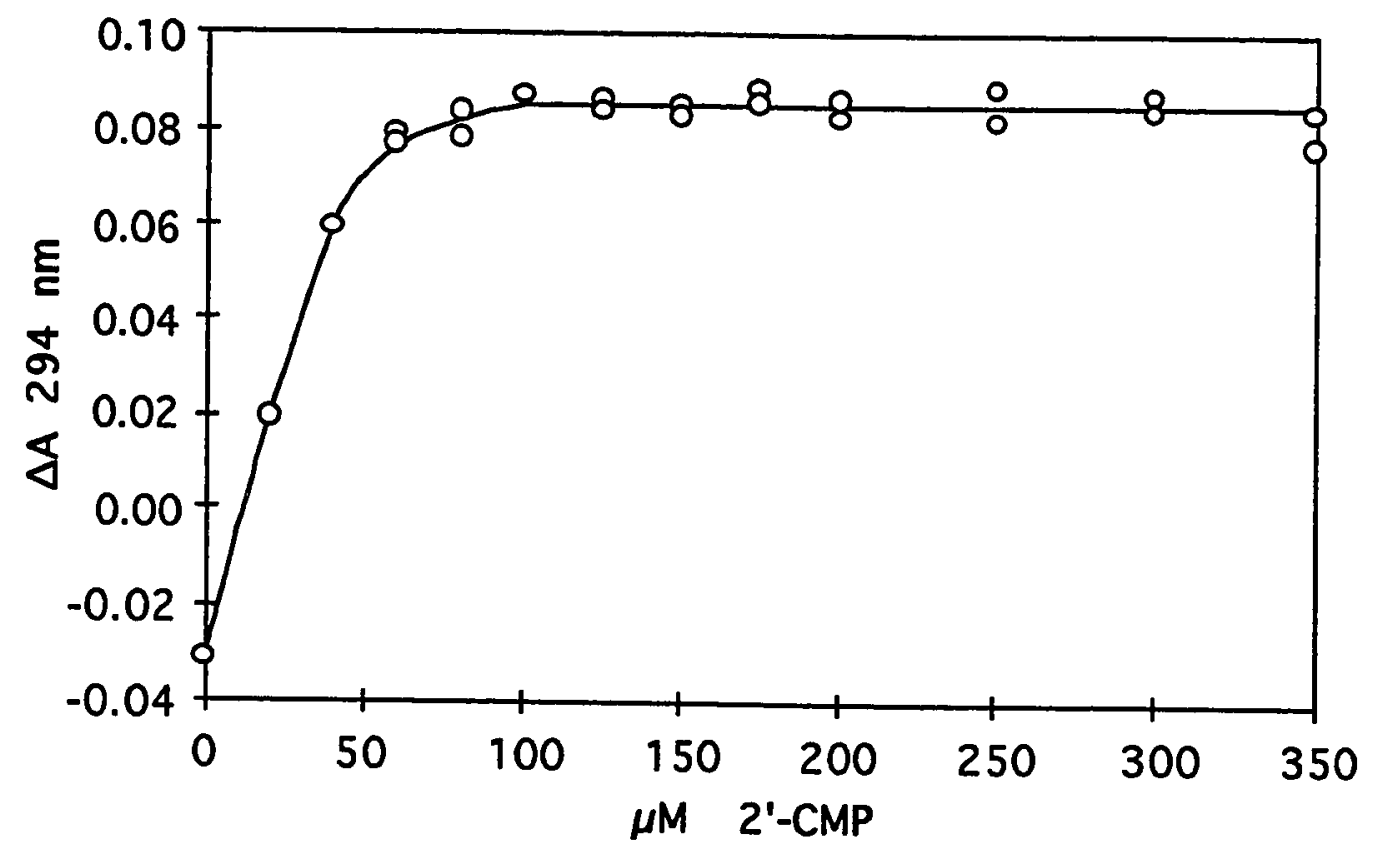

Figure 17: Saturation profile for 2'-CMP (0.05 M acetate) in the presence of 31.7 $\mu \mathrm{M}$ RNase $\mathrm{A}$ at $\mathrm{pH} 4$ and $17^{\circ} \mathrm{C}$. The change of absorbance at $294 \mathrm{~nm}$ for 2'-CMP in the absence and presence of $31.7 \mu \mathrm{M}$ RNase A reflects the binding of the inhibitor to the enzyme. 
than $100 \mu \mathrm{M}(50,75 \mu \mathrm{M})$, and two are higher $(200,300 \mu \mathrm{M})$.

\subsection{Urea-Induced Unfolding of RNase $A$ in the Presence of Various Concentrations of 2'-CMP as Monitored by Fluorescence and Absorbance Spectroscopy}

The urea-induced unfolding of RNase A in the presence of $100 \mu \mathrm{M}$ 2'-CMP had been already examined (Figure 15). The four other concentrations of 2'CMP that had been selected based upon the saturation profile were also examined. All of the experimental procedures were identical to those used in the $100 \mu \mathrm{M}$ 2'-CMP experiment except that the 2'-CMP concentration was different in each. An example of the results is given in Figure 18. The overall results (the $\mathrm{Cm}$ and $\mathrm{m}$ values) are given in Table 1A. The data shows that below saturating concentrations, the $\mathrm{Cms}$ move to higher urea concentrations with increasing 2'-CMP concentrations. At the minimum saturating concentration and above, the $\mathrm{Cms}$ are, within experimental error, the same. This result clearly indicates that the binding of the inhibitor to the active site stabilizes the protein.

The protein's ability to bind 2'-CMP was also measured with these solutions. For this purpose, the difference absorbance amplitude at $272 \mathrm{~nm}$ was chosen. Three criterions were considered in selecting this wavelength: 1) any absorbance change at this wavelength must only reflect the degree of 2'-CMP binding, and must not reflect changes in the tertiary structure of the protein, 2) the signal must obey Beer's law, and 3) the signal must be of reasonable intensity. As previously shown (Figure 15), the initial and complete exposure of the tyrosine residues of the protein to solvent in the absence of 2'-CMP are around $4 \mathrm{M}$ and $7 \mathrm{M}$ urea, respectively. Any absorbance change associated with denaturation will be observed in this range (Figure 19A). This was 


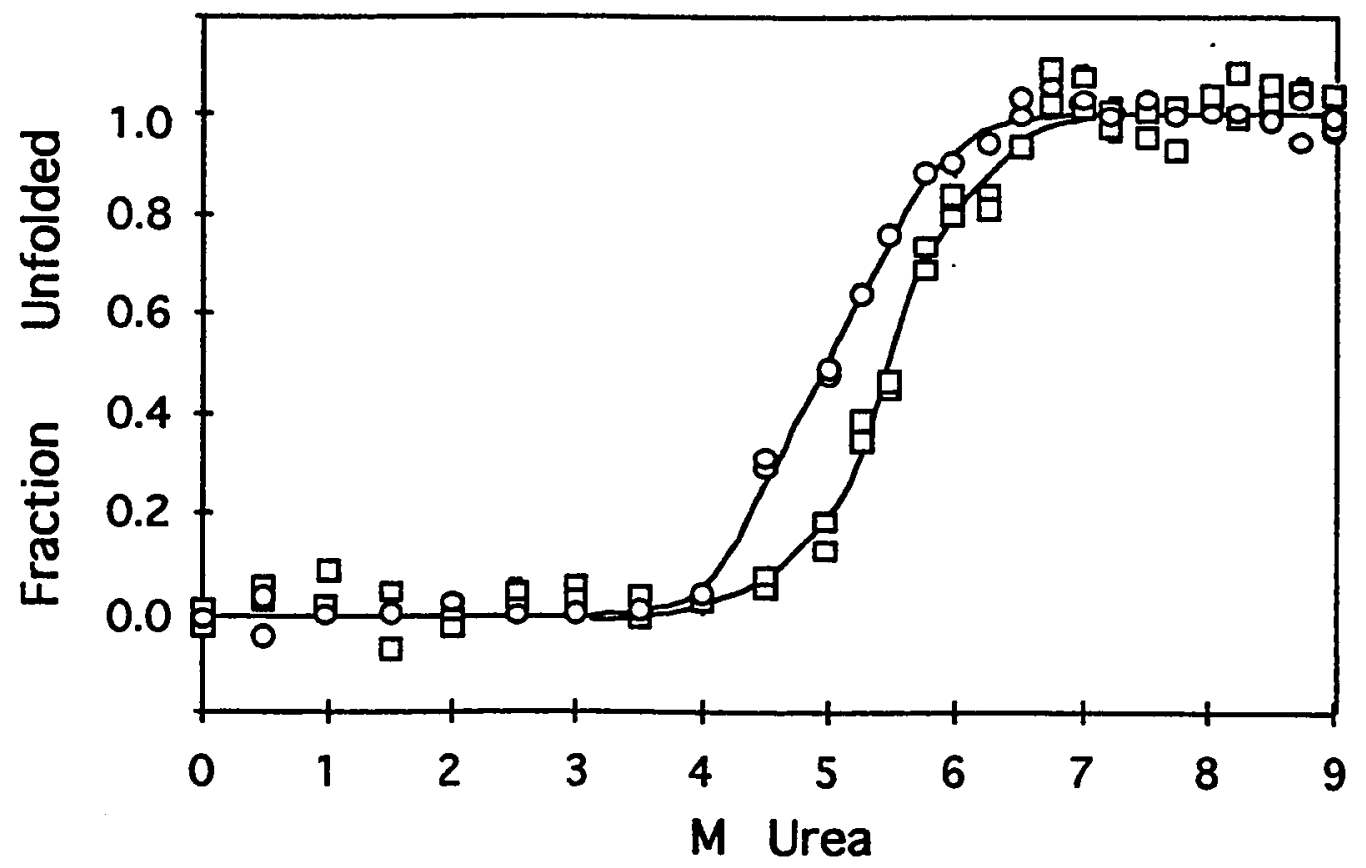

Figure 18: Fraction of unfolded representations for the fluorescencemonitored urea denaturation of RNase $A(31.7 \mu \mathrm{M})$ in the absence (Ō) and presence ( $\square$ ) of $200 \mu \mathrm{M} 2^{\prime}-\mathrm{CMP}$ at $\mathrm{pH} 4$ and $17^{\circ} \mathrm{C}$. The curves drawn through the data have no statistical meaning. 
Table 1: Parameters obtained from urea unfolding of RNase $A(31.7 \mu \mathrm{M})$ in the absence and presence of various concentrations of 2'-CMP and $350 \mu \mathrm{M}$ 5'-CMP at $\mathrm{pH} 4$ and $17^{\circ} \mathrm{C}$.

A. Monitored by fluorescence spectroscopy

$\begin{array}{lll}2^{\prime}-\mathrm{CMP}(\mu \mathrm{M}) & \mathrm{Cm} & \mathrm{m} \\ 0 & 5.00 & -1.50 \\ 50 & 5.05 & -2.05 \\ 75 & 5.14 & -1.78 \\ 100 & 5.41 & -1.62 \\ 200 & 5.54 & -1.85 \\ 300 & 5.50 & -1.19 \\ & & \\ 5^{\prime}-\mathrm{CMP}(\mu \mathrm{M}) & \mathrm{Cm} & \mathrm{m} \\ 350 & 5.48 & -0.45\end{array}$

B. Monitored by absorbance spectroscopy

2'-CMP $(\mu \mathrm{M}) \quad \mathrm{Cm} \quad \mathrm{m}$

$50 \quad 5.18 \quad-1.62$

$75 \quad 5.18 \quad-1.62$

$200 \quad 5.25 \quad-1.33$ 


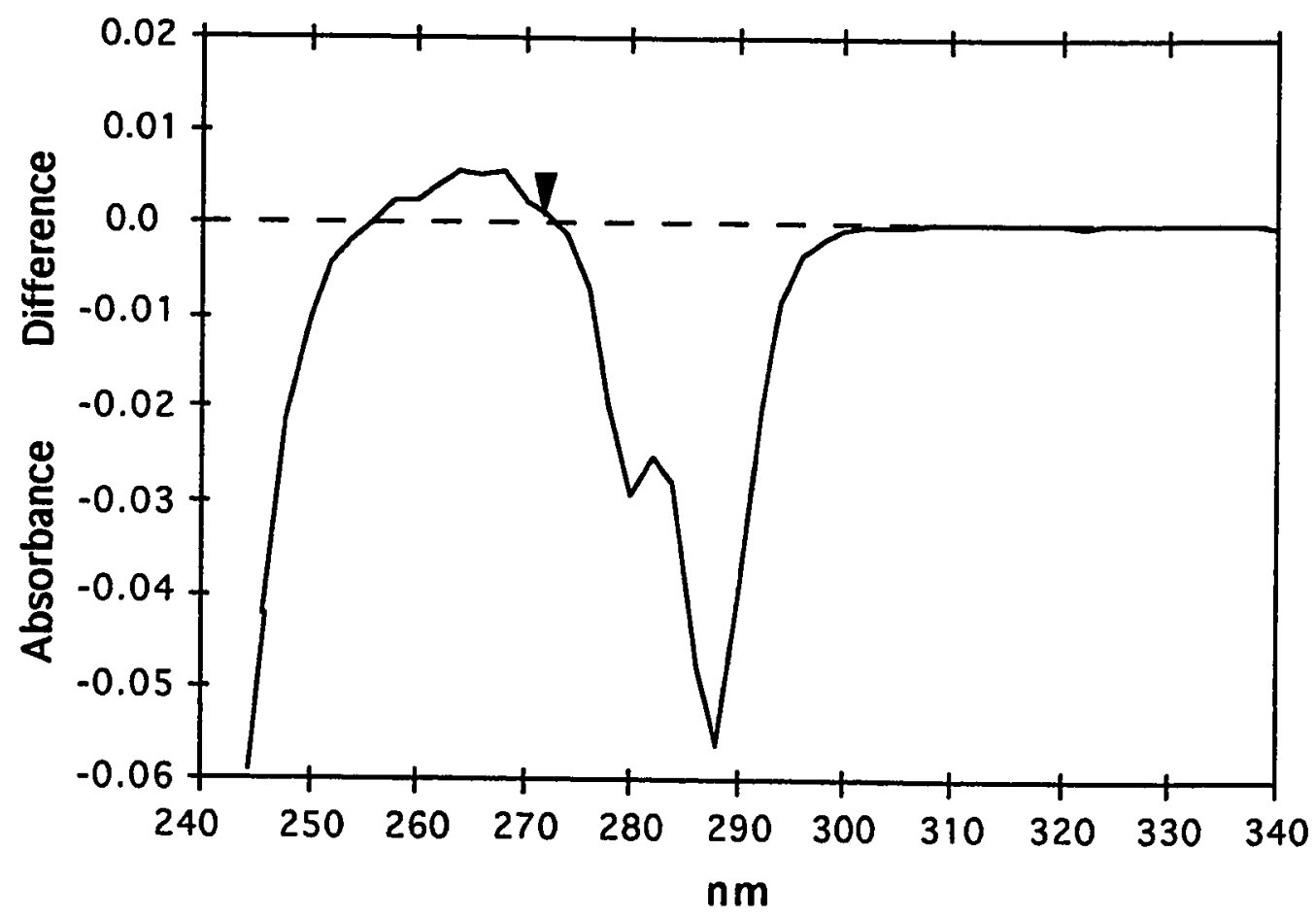

Figure 19A: Absorbance spectral difference between native (in $4 \mathrm{M}$ urea) and denatured (in $7 \mathrm{M}$ urea) RNase $\mathrm{A}$. Absorbance spectrum for native RNase $\mathrm{A}$ $(31.7 \mu \mathrm{M})$ is subtracted from that for denatured RNase $A(\mathrm{pH} \mathrm{4,} 0.05 \mathrm{M}$ acetate at $20^{\circ} \mathrm{C}$ ). The zero absorbance change at $272 \mathrm{~nm}$ (indicated by an arrow) in this difference spectrum means that the signal change at this wavelength is independent of the change in the tertiary structure of RNase A. 


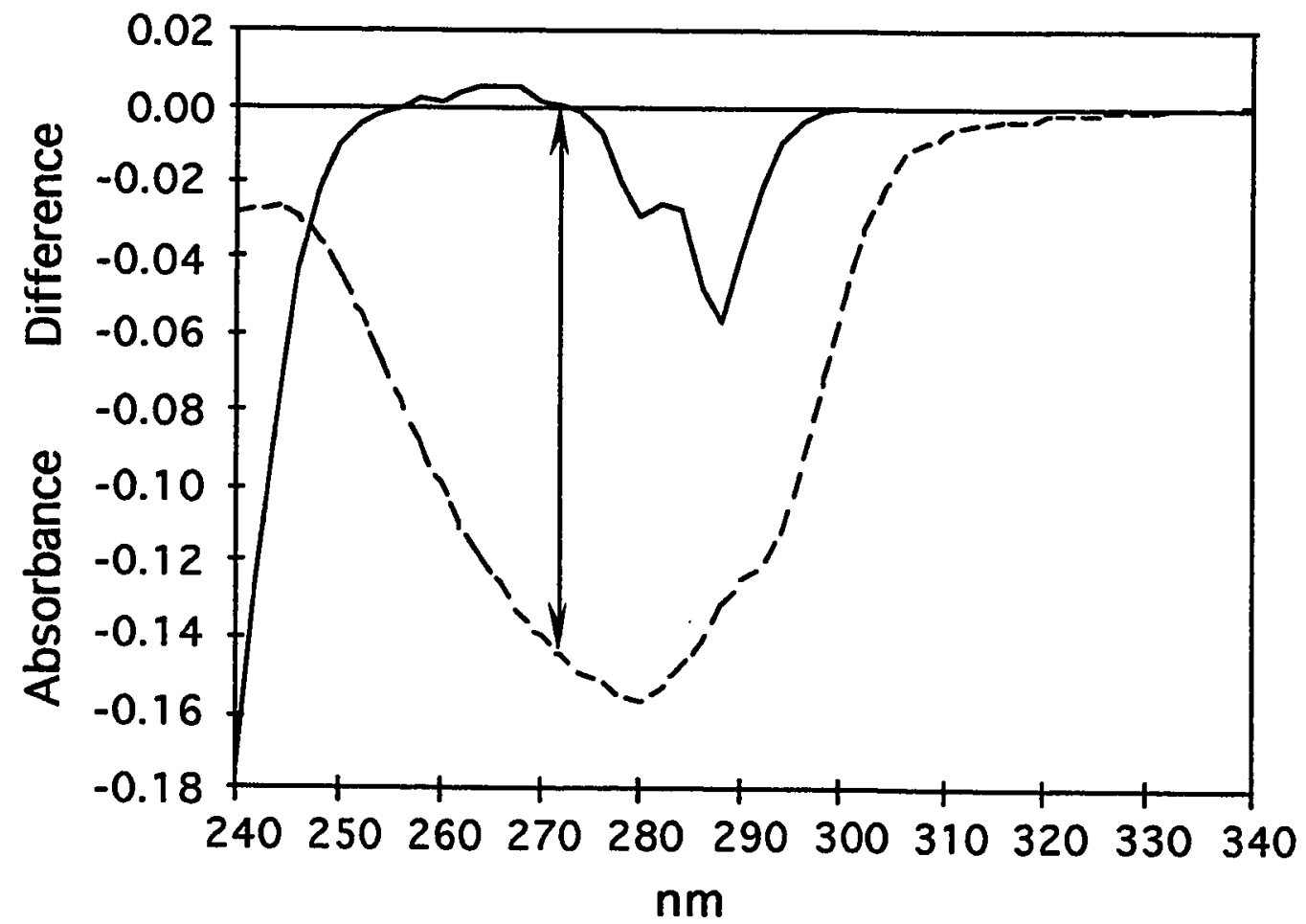

Figure 19B: Absorbance spectral difference for 2'-CMP in the absence and presence of RNase A (--) superimposed on the data from Figure 19A (-). The difference absorbance spectrum (Figure 16) was obtained by subtracting the spectrum for $100 \mu \mathrm{M} 2^{\prime}$-CMP from that for the mixture of $31.7 \mu \mathrm{M}$ RNase $\mathrm{A}$ and $100 \mu \mathrm{M} 2^{\prime}-\mathrm{CMP}$ at $\mathrm{pH} 4$ and $17^{\circ} \mathrm{C}$. The difference in the absorbance at 272 $\mathrm{nm}$ between both difference spectra is indicated by the arrow. The data clearly shows that the degree of the binding of 2'-CMP to RNase A in urea solutions will not be influenced by the change in the absorbance of tyrosine residues that accompany denaturation. 
examined by subtracting the spectrum for the protein in $4 \mathrm{M}$ urea from that for the protein in $7 \mathrm{M}$ urea. The difference represents the change in the tertiary structure of the protein. Figure 19A shows that the absorbance at 272 nm does not change. Comparison to the difference spectrum obtained by subtracting the spectrum for $100 \mu \mathrm{M} 2$ 2'-CMP only from the spectrum for the mixture of $31.7 \mu \mathrm{M}$ protein and $100 \mu \mathrm{M}$ 2'-CMP (dash line in Figure 19B) reveals that the absorbance signal at $272 \mathrm{~nm}$ is large enough to show the degree of the binding of 2'-CMP to RNase $A$ and it will not be influenced by changes in the absorbance of the tyrosine residues that accompany denaturation. Also, the absorbance at $272 \mathrm{~nm}$ is small enough to obey Beer's law within the 2'-CMP concentration range examined.

Any fluorescence change at $305 \mathrm{~nm}$ corresponds to the degree of exposure of the tyrosine residues in RNase A, whereas the alteration of the absorbance from different spectra at $272 \mathrm{~nm}$ represents the degree of 2'-CMP binding to RNase A. Coincidence of these data would lend further support that 2'-CMP stabilizes RNase A. Figure 20A shows the binding of $200 \mu \mathrm{M} 2$ '-CMP to RNase A for a series of urea concentrations superimposed on the corresponding fluorescence data. The binding curve at $272 \mathrm{~nm}$ is composed of three portions: pretransition, transition, and posttransition. In the pretransition region, the absorbances from difference spectra at $272 \mathrm{~nm}$ decrease, and the decline is coincident with the effect of a series of concentrations of urea on the absorbance of $200 \mu \mathrm{M}$ 2'-CMP (Figure 20B). Hence, it is reasonable to think that a decrease of the absorbances in the pretransition region is not due to a loss of binding of 2'-CMP to RNase $A$, but due to a solvent effect on the unbound 2'-CMP. In the transition region, the absorbance decreases because the concentration of native protein decreases. In the posttransition region, the decreased absorbances tend to follow the solvent effect as well. Thus, any 


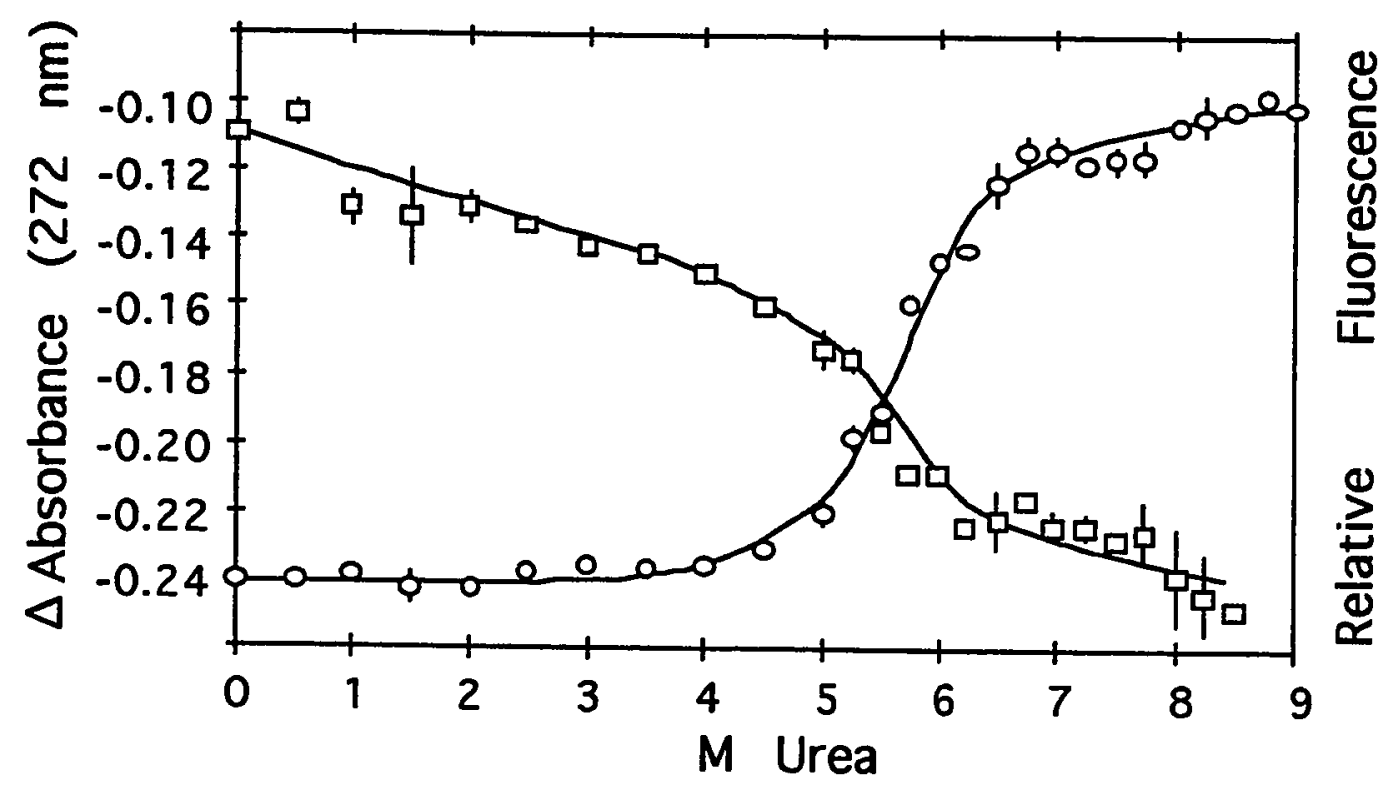

Figure 20A: Urea denaturation data for RNase $\mathrm{A}(31.7 \mu \mathrm{M})$ in the presence of $200 \mu \mathrm{M} \mathrm{2}$ - $\mathrm{CMP}$ at $\mathrm{pH} 4$ and $17^{\circ} \mathrm{C}$. The circles represent the fluorescence $(280 / 305 \mathrm{~nm})$ for RNase A with 2'-CMP and the squares represent the absorbance difference at $272 \mathrm{~nm}$ between 2'-CMP in the absence and presence of RNase A. Error bars indicate the range of data taken from two independent measurements and the symbol indicates the average of these values. Absence of error bars indicates that the range of data is smaller than the height of the symbol. The curves drawn through the data have no statistical meaning. 


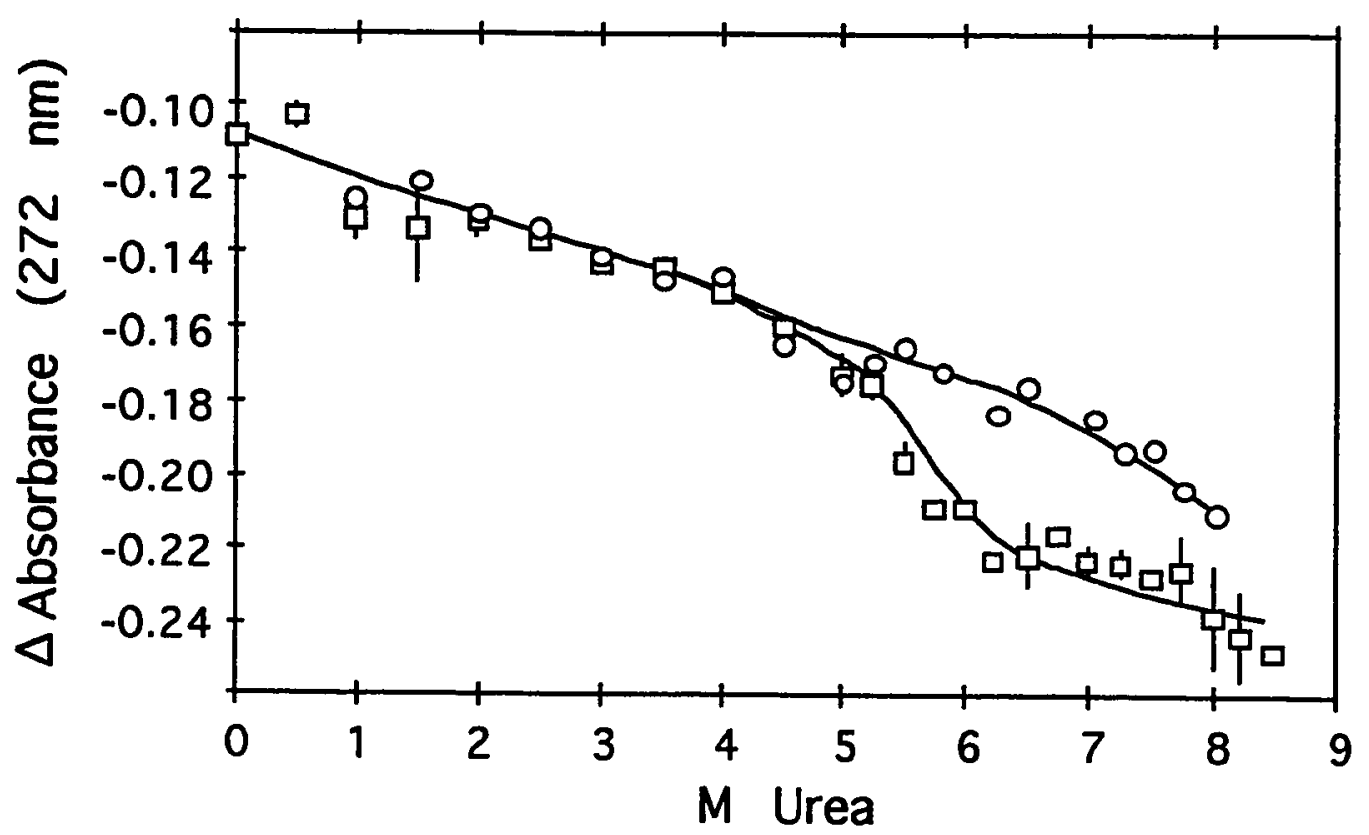

Figure 20B: Urea denaturation data for RNase $\mathrm{A}(31.7 \mu \mathrm{M})$ in the presence of $200 \mu \mathrm{M} 22^{\prime}-\mathrm{CMP}$ and the effect of urea on the absorbance of $200 \mu \mathrm{M} 2{ }^{\prime}-\mathrm{CMP}$ in the absence of RNase A at $\mathrm{pH} 4$ and $17^{\circ} \mathrm{C}$. The circles represent the absorbance difference $(272 \mathrm{~nm})$ for 2'-CMP in various concentrations of urea and that in 0 $M$ urea. The squares represent the absorbance difference at $272 \mathrm{~nm}$ between 2'-CMP in the absence and presence of RNase A (from Figure 20A). The data from the former was offset to match the initial absorbance value obtained from the difference data. This is necessary to compensate for the decrease in signal associated with 2'-CMP binding. Error bars indicate the range of data taken from two independent measurements and the symbol indicates the average of these values. Absence of error bars indicates that the range of data is smaller than the height of the symbol. The curves drawn through the data have no statistical meaning. 
absorbance change in this region is most likely due to a solvent effect and not due to a change in binding.

Data were evaluated by both linear extrapolation and curve-fitting. The results are given in Table 1B. Comparison of Table 1A with Table 1B shows that the $\mathrm{Cm}$ values obtained with the different techniques yielded somewhat different values. However, corresponding plots for the fraction of unfolded molecules as a function of urea concentration (not shown) are essentially coincident within experimental error. These results and the fact that the absorbance-monitored binding data has a significantly smaller signal-to-noise ratio than that obtained from the fluorescence data (see Figure 20A) lead to the conclusion that the differences in the $\mathrm{Cm}$ values are due to the larger error associated with the absorbance data. For this reason, only the fluorescencemonitored data will be used in the discussion that follows.

\subsection{Determination of a Saturation Profile for 5'-CMP Binding to RNase A}

Since the results showed that 2'-CMP stabilized RNase A against ureainduced unfolding, the next logical step was to examine the mechanism of how this inhibitor works. NMR results show that the movement of the N-terminal helix away from the body of RNase $A$ is one of the first steps that occurs during thermal-unfolding of RNase A (29). Since 2'-CMP is known to interact strongly with the $\mathrm{N}$-terminal helix, it is reasonable to assume that 2'-CMP stabilizes RNase A against urea-induced unfolding by tightly binding the $\mathrm{N}$ terminal helix. The binding model derived from x-ray studies (Figure 12) clearly shows that the phosphate group interacts with Lys-41, His-12 and His119 when 3'-CMP binds to the active site of RNase A. Since His-12 is located in $\mathrm{N}$-terminal helix, this interaction should contribute to the stabilization of 
RNase A. The 5'-CMP inhibitor was selected in order to test whether the strong interaction of the phosphate group of 2'-CMP with His-12 is responsible for the stabilization of RNase A against urea-induced unfolding. Assuming that the nucleoside portion of 5'-CMP binds to RNase A in the same manner that 2'CMP does (see Figure 12), then the 5'-phosphate of 5'-CMP will be unavailable to interact with His-12. If this is the case and if 5'-CMP does not stabilize RNase A against urea-induced unfolding, the hypothesis is supported. If this is not the case, then the mechanisms by which the inhibitors interact with RNase A and of how they stabilize RNase A against denaturation are more complicated.

In order to determine whether 5'-CMP stabilizes RNase A against unfolding, the minimum concentration of 5'-CMP required for saturation must be obtained. The saturation profile is given in Figure 21A. The data suggest that 5 -CMP saturation is achieved at $350 \mu \mathrm{M}$. Unfortunately, the maximum concentration of 5'-CMP was limited to $500 \mu \mathrm{M}$, since the absorbances for concentrations above this value violate Beer's law. Failure to examine concentrations higher than $500 \mu \mathrm{M}$ prevents confirmation of the saturation point from the profile itself. In order to ensure that $350 \mu \mathrm{M}$ is the minimum concentration necessary to achieve saturation, a semilog plot (Figure 21B) was constructed from the original data (Figure 21A). The semilog plot indicates that saturation has been achieved within the examined concentrations, as the curve levels off at the higher concentrations.

\subsection{Urea-Induced Unfolding of RNase $A$ in the Presence of $350 \mu \mathrm{M}$} 5'-CMP as Monitored by Fluorescence Spectroscopy

To test the contribution of 2'-phosphate group of 2'-CMP in the stabilization of RNase A, urea-induced unfolding of RNase A in the presence of $350 \mu \mathrm{M} 5$ 'CMP was examined by fluorescence spectroscopy. This concentration was 


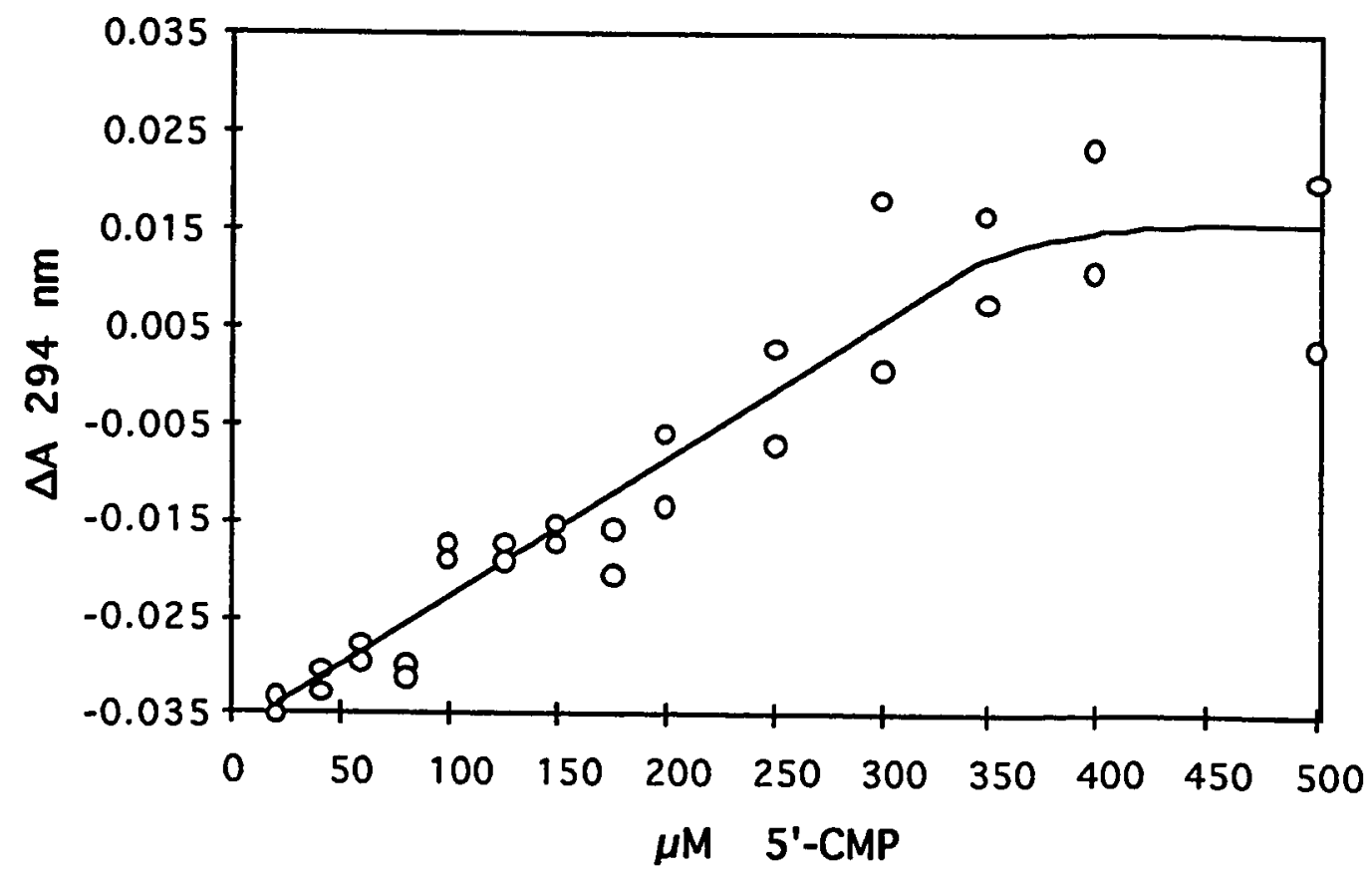

Figure 21A: Saturation profile for 5'-CMP $(0.05 \mathrm{M}$ acetate $)$ in the presence of $31.7 \mu \mathrm{M}$ RNase $\mathrm{A}$ at $\mathrm{pH} 4$ and $17^{\circ} \mathrm{C}$. The absorbance difference at $294 \mathrm{~nm}$ between 5'-CMP in the absence and presence of RNase A represents the binding of 5'-CMP to RNase A. The curve drawn through the data has no statistical meaning. 


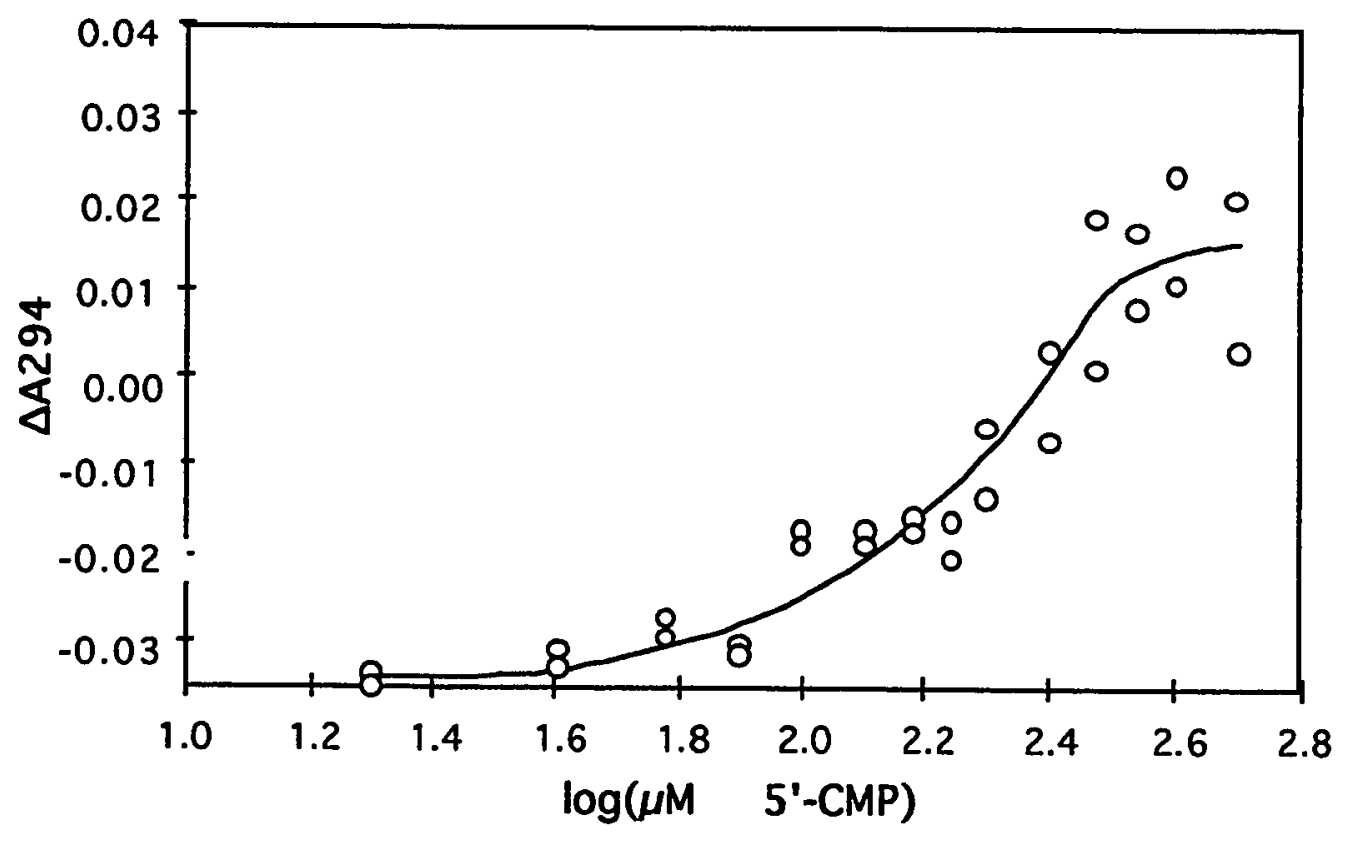

Figure 21B: Semilog representation of the saturation profile for 5'-CMP $10.05 \mathrm{M}$ acetate) in the presence of $31.7 \mu \mathrm{M}$ RNase $\mathrm{A}$ at $\mathrm{pH} 4$ and $17^{\circ} \mathrm{C}$. The data represents the absorbance difference at $294 \mathrm{~nm}$ between 5'-CMP in the absence and presence of RNase $A$ as a function of the logarithm of the 5'-CMP concentration. The curve drawn through the data has no statistical meaning. 
selected because it represents the lowest concentration of 5'-CMP necessary to achieve saturation. This allows for the direct comparison of the results to those obtained for 2'-CMP binding with the best signal-to-noise possible.

The $\mathrm{Cm}$ value for RNase $\mathrm{A}$ in the presence of $350 \mu \mathrm{M}$ of 5'-CMP is similar to that obtained in the presence of saturating concentrations of 2'-CMP (Table 1A). This result is not in agreement with the original hypothesis and implies that the mechanism of how the inhibitors stabilize RNase A against ureainduced unfolding is more complicated. 


\section{DISCUSSION}

\subsection{The Quenching of the Intrinsic Fluorescence of RNase $A$ by}

2'-CMP

A comparison of the fluorescence emission spectrum for a solution containing both RNase A and 2'-CMP with that for RNase A without 2'-CMP shows that the inhibitor quenchs about $68 \%$ of the intrinsic fluorecence of the protein (Figure 13). The quenching effect by 2'-CMP is also observed during unfolding of RNase $A$ in urea solutions (Figure 14). Possible explanations for the observed quenching are discussed below.

One possible clue comes from Chen and Cohen's finding (58) that the tyrosine fluorescence of RNase $A$ is quenched by phosphate ions. Based upon this evidence, it would be reasonable to assume that the monophosphate portion in 2'-CMP may play a role in the quenching of the intrinsic

fluorescence of RNase A. Chen and Cohen also stated that the mechanism of quenching may be relative to the collisions of tyrosine residues in the native protein with phosphate ions, and the degree of quenching is due to the degree of the accessibility of individual tyrosine residues to the quenching molecules. RNase A contains six tyrosine residues, three of which are nonfluorescent in the native state, since they are buried within the structure. The fluorescence emitted by the other three exposed tyrosine residues may be easily perturbed by the quenching molecules, since these residues are near or on the surface of the protein.

Fluorescence quenching could involve energy transfer from the tyrosines to the cytidine ring. For example, tryptophan fluorescence in apomyoglobin can be quenched by the binding of anilinonaphthalene sulfonate (ANS) dye (59). The best explanation for this effect is that the excitation energy is 
transferred from the aromatic amino acids of the protein to the bound ANS.

Another possible explanation is the inner filter effect caused by instrumental artifact (60), since all fluorescence measurements were made with right angle illumination. Since 2'-CMP has a strong absorption from $\mathbf{2 8 0}$ $\mathrm{nm}$ to $300 \mathrm{~nm}$ (Figure 16) where RNase A is excited, theoretically, this high absorbance could reduce the fluorescence amplitude through excessive absorption of the exciting light.

Further experimentation is required to determine the relative contributions of these three possibilities.

\subsection{The Higher Binding Affinity of 2'-CMP to RNase $\mathrm{A}$ at $\mathrm{pH} 4$}

The saturation profiles for 2'-CMP and 5'-CMP reflect the degree of binding of both inhibitors to the enzyme. By comparison of these two profiles (Figure 17 and Figure 21A), one can see that the binding abilities for 2'-CMP and 5'CMP are quite different. The binding of 2'-CMP requires only $100 \mu \mathrm{M}$ to achieve saturation, while the binding of 5'-CMP needs $350 \mu \mathrm{M}$ to reach saturation under the same experimental conditions. The only difference in the structures of these molecules is in the position of a phosphate group, which is evidently responsible for the difference in the binding affinity. Possible explanations for this result are examined below.

It has been found that 2'-CMP is one of the most powerful competitive inhibitors of RNase $A$ and it specifically binds at the active site of RNase $A$ with a ratio of $1: 1(36,61)$. In contrast, 5'-CMP shows mixed inhibition that is more noncompetitive than competitive (62), and thus it may bind to a second binding site as proposed by Schellman (63) or perhaps to both sites. Hence, based on the previous data, as well as the results in the present studies, it is possible that the binding affinity of 2'-CMP to RNase $A$ is higher than that of 
5'-CMP due to the different affinity constants for the same or different sites.

The equilibrium binding constants or dissociation constants of most inhibitors to RNase A have been determined within a certain range of $\mathrm{pH}$ (6367). The previous work shows that at $\mathrm{pH} 7.6$, the ability of all pyrimidine 2'-, 3'-, and 5'-monophosphate nucleotides to bind to RNase A is about equal (67). The binding constant at pH 4 for $2^{\prime}-\mathrm{CMP}$ is equal to $3.83 \times 10^{3} \mathrm{M}^{-1}$ (65). Unfortunately, the corresponding data for 5'-CMP is not found in the published literature. Extrapolation of the $\mathrm{pH} 7.6$ data to $\mathrm{pH} 4$ is not possible, as the changes in binding affinity for the different compounds are nonlinear and depend on the particular nucleotide monophosphate (68). Hence, confirmation awaits further experimentation.

A model, based primarily on x-ray data, for nucleotide binding to RNase A was first proposed during the 1960's. The binding involves electrostatic interactions between the anionic phosphate of the nucleotide and two histidine residues at the active site of the enzyme (66). The binding also involves hydrogen bonds between the cytidine ring and Thr-45 of RNase A. There is no apparent interaction between RNase and the ribose ring of nucleotide (69-70). The side chain of Lys-66 is involved in the binding of 5'phosphates of inhibitors (70), which supports the existence of an additional phosphate-binding site in RNase A. Recent studies on the crystal structures of the complexes of RNase and mononucleotides and dinucleotides show several new findings (71-75). First, the cytidine and the phosphate group of the dinucleotide are present in the catalytic site and the guanine is bound in a second binding site. In this second site, the guanine forms two hydrogen bonds to Thr-45 which is also involved in pyrimidine binding. Second, His-119 occupies two alternative positions, $A$ and $B$ conformations, and 2'-CMP binding stabilizes the imidazole ring when the structure is in the A conformation. 
Third, His-12 and Lys-41 strongly interact with the 2'-oxygen of the ribose ring, whereas the previously determined crystal structures of the complexes did not show that the ribose ring of $3^{\prime}$-CMP is involved in the interaction with the active site of RNase A. Fourth, conserved water binding sites in this protein are also found. Some of the water molecules appear to play a role in the binding of the N-terminal helix to the body of the protein, and thus would play a role in the stabilization of the active site. Lastly, in the 2'-CMP complex, the 2'-oxygen interacts weakly with the active site, and both Lys-41 and Gln-11 are bound to the phosphate by hydrogen bonds. Although the newly determined crystal structures of RNase A-inhibitor complexes provide a more detailed description of binding, they do not provide an explanation of why the binding affinity of 2'-CMP to RNase $A$ is higher than that of 5'-CMP. However, they provide evidence that there is a second and adjacent nucleotide binding site in RNase A. In this model, Thr-45 is a common amino acid for the binding of the cytidine rings at both sites, and Lys-66 rather than Lys-41 is bound to phosphate at the second binding site. This model also provides evidence that ribose ring is involved in the binding of inhibitors, and in addition to His-12, His-119, and Lys-41, Gln-11 is bound to the phosphate by hydrogen bonds at the substrate binding site. It appears that the number of amino acids involved in inhibitor binding at the substrate binding site is greater than that at the second binding site. The new model presented above shows a significant number of interactions between the nucleotides and RNase $A$ at both sites, but the differences do not appear significant enough to explain the differences in binding.

\subsection{The Stabilization of RNase $A$ against Urea-Induced Unfolding} by 2'-CMP and by 5'-CMP Binding 
The data in Table 1 clearly show that both 2'-CMP and 5'-CMP stabilize RNase A against urea denaturation at $\mathrm{pH} 4,17^{\circ} \mathrm{C}$. The degree of 2'-CMP stabilization increases with increasing 2'-CMP concentration up to saturation and remains constant with increasing 2'-CMP concentrations after this point. This suggests that 2'-CMP stabilizes RNase A against denaturation by binding to the active center of the enzyme. These results support Nelson and Hummel's proposal that an early stage in urea-induced denaturation may involve the disruption of the local native conformation at the active site $(36,42)$.

At saturating concentrations, both 5'-CMP and 2'-CMP stabilize RNase A to the same extent (Table 1 and Figure 22). This lends further support for the idea that the stabilization of the active center serves to stabilize the overall structure of the protein.

The stabilization of RNase A against urea-induced unfolding has been found not only for the binding of 2'-CMP but also for the binding of other anions (36) at the catalytic site such as phosphate, sulfate, and pyrophosphate. Since the degree of binding of 2'-CMP to RNase A is several orders of magnitude greater than that of phosphate, the cytosine moiety must also be responsible for the higher degree of binding.

Barnard (44) found that one urea molecule competitively, but not very effectively, interacts with RNase at the substrate binding site at urea concentrations lower than those required to denature the protein. Benz and Roberts's results (27) indicate that at least two urea molecules interact with each RNase molecule at low urea concentrations, although any associated conformational change does not represent an initial unfolding of the protein. Our results do not distinguish which one is correct.

In contrast to Barnard's observation (44) that urea serves as a competitive inhibitor at low concentrations, Liu and Tsou (45) found that GdnCl acts as a 


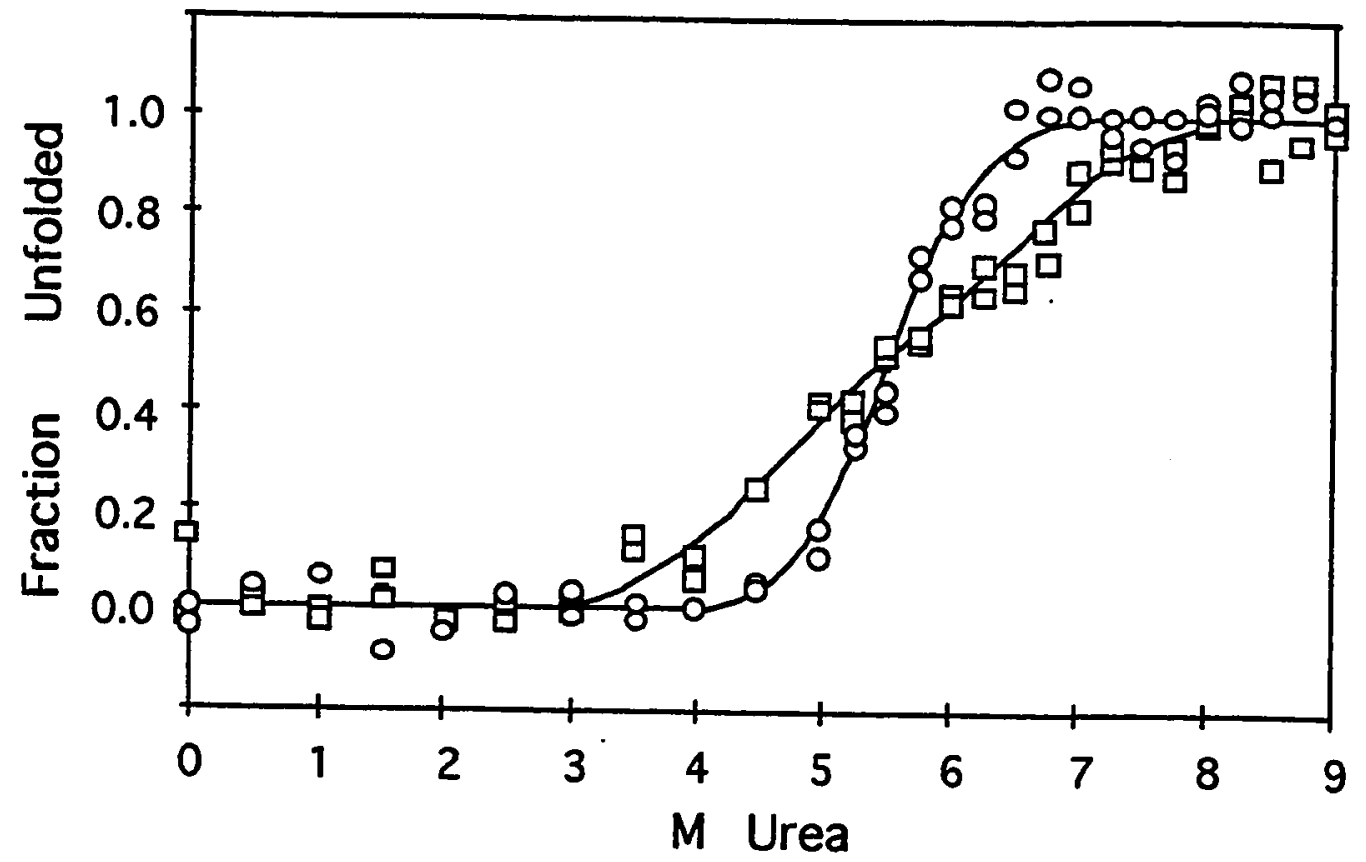

Figure 22: Fraction unfolded representation of the fluorescence-monitored urea denaturation of RNase $A$ in the presence of saturating concentrations of 2'-CMP (O) and 5'-CMP (प) at $\mathrm{pH} 4$ and $17^{\circ} \mathrm{C}$. RNase $A$ was $31.7 \mu \mathrm{M}, 2^{\prime}-\mathrm{CMP}$ was $100 \mu \mathrm{M}$, and $5^{\prime}-\mathrm{CMP}$ was $350 \mu \mathrm{M}$. The curves drawn through the data have no statistical meaning. 
denaturant, and not a competitive inhibitor at low concentrations. This difference between urea and $\mathrm{GdnCl}$ may be explained by Kasumov's finding (76) that the pathways of unfolding of RNase A by urea and $\mathrm{GdnCl}$ are somehow different, at least at low concentrations of these denaturants. If this is true, electrostatic interactions may be important, since $\mathrm{GdnCl}$ is charged whereas urea is not.

The binding of 2'-CMP to RNase A has been used as a probe for the detection of the intermediate(s) formed during refolding of RNase $A(10,12)$ and does not affect the folding kinetics. In addition, the binding of 2'-CMP does not affect the thermal equilibrium unfolding transitions (77). Our results indicate that the binding of 2'-CMP cannot serve as a probe for the detection of the intermediates formed in urea-induced equilibrium unfolding of RNase A, since it stabilizes the protein. There are two possible explanations for this difference. First, the kinetic pathway is dominated by the activation free energies and not the relative free energies of the intermediate states. It is not unreasonable that 2'-CMP binding serves to lower the free energy of the native state without affecting the free energies of intermediate states or the activation energies between states. Second, the dissociation constant for 2'CMP-RNase A complex is a function of temperature. Since the binding of 2'CMP to RNase A decreases with increasing temperature, any stabilization will decrease with increasing temperature and might not be observed in thermal unfolding.

The presence of 2'-CMP at the active site protects RNase A not only against urea-induced unfolding, but also against protease digestion such as trypsin, chymotrypsin, and subtilisin (78). The binding of a competitive inhibitor like 2'-CMP, or 3'-CMP itself is thought to induce a small conformational change in RNase A (79) that serves to increase protease resistance. 


\subsection{The Less-Cooperative Transition in Urea-Induced Unfolding of}

RNase $A$ in the Absence of 2'-CMP and in the Presence of 5'-CMP The competitive inhibitor, 2'-CMP, stabilizes RNase A against urea-induced unfolding with slightly increased $m$ values (Table 1 ) as compared to that without 2'-CMP. Although the effect is small, it is statistically significant. According to Schellman's model (54), the m value is directly proportional to Ad-An, where Ad and An account for the solvent-accessible surface area of a particular protein in the denatured state and the native state, respectively. The larger the $m$ value, the greater the difference in the exposed surface area between the denatured and the native states. In the presence of 2'-CMP, the higher $\mathrm{m}$ values would indicate that either RNase A more effectively exposes the surface area of its denatured state to solvent, or that the native structure is compacted to a higher degree. The latter explanation is more likely, and is supported by the fact that protease resistance is enhanced in the presence of 2'-CMP $(78,79)$. Alternatively, the lower $m$ value observed in the absence of 2'-CMP may indicate that partially folded intermediates are populated in the absence of 2'-CMP, and the presence of 2'-CMP prevents their formation (54).

Only the $300 \mu \mathrm{M}$ 2'-CMP data did not follow this trend (Table 1A). The low $\mathrm{m}$ value for these data may be explained by one or both of the following reasons. First, the data obtained for $300 \mu \mathrm{M}$ 2'-CMP had a poor signal-to-noise ratio as a result of the severe inner filter effect at this inhibitor concentration. The low value for m may reflect a lower degree of accuracy associated with the analysis of this data. Second, nonspecific binding of 2'-CMP to the denatured state at high 2'-CMP concentrations may result in a slight compaction of the denatured state.

The 5'-CMP inhibitor also stabilizes RNase A against urea-induced unfolding at the saturating concentrations with a $\mathrm{Cm}$ value similar to that of 
2'-CMP (Figure 22, Table 1A). However, the transition in the presence of 350 $\mu \mathrm{M}$ 5'-CMP is considerably less cooperative than that in the presence of $100 \mu \mathrm{M}$ 2'-CMP. In fact, the $\mathrm{m}$ value obtained from the 5'-CMP experiment is nearly five times smaller than those obtained from the 2'-CMP experiments. There are two possible explanations for this. First, the lower cooperativity may indicate that partially folded intermediates are populated. If this is the case, 5'-CMP serves as an intermediate stabilizer. Second, according to Schellman's model, the reduced cooperativity indicates that the difference in the solvent exposed surface area between the native and the denatured states is smaller in the presence of 5'-CMP than in the presence of 2'-CMP or in the absence of 2'CMP. Since 5'-CMP binds to RNase A less tightly than 2'-CMP does, it is unlikely that 5'-CMP reduces the solvent exposed surface area of the native state to a greater degree than 2'-CMP does. Hence, the effect would have to be on the denatured state. The only reasonable explanation for this would be nonspecific binding of 5'-CMP to the denatured state, which causes the denatured protein to be more compact than that in the presence of 2'-CMP. The fact that this is rather unlikely, our working model is that 5'-CMP serves to stabilize intermediate states along the folding pathway. 


\section{CONCLUSIONS}

On the basis of the results presented in this thesis, several conclusions can be made and are summarized as follows: The fluorescence of native RNase $A$ is quenched in the presence of 2'-CMP. The minimum concentrations of 2'-CMP and 5'-CMP required for the saturation of RNase $\mathrm{A}$ are $100 \mu \mathrm{M}$ and $350 \mu \mathrm{M}$, respectively. The binding affinity of 2'-CMP is much higher than that of 5'CMP at pH 4 and $17^{\circ} \mathrm{C}$. Both 2'-CMP and 5'-CMP can stabilize RNase A against urea-induced unfolding. Within experimental error, the degree of the stabilization by 2'-CMP follows the increase in 2'-CMP concentration up to saturation, and remains constant with increasing 2'-CMP concentration above saturation. This indicates that this effect is exerted through the binding of 2'CMP to the active site of RNase A. The less cooperative transition in the absence of 2'-CMP indicates that partially folded intermediates are populated and that the presence of 2'-CMP prevents their formation. In contrast to 2'CMP, 5'-CMP may serve as an intermediate stabilizer.

The above experimental conclusions envoke two interesting questions which should be investigated further. What is the mechanism by which 2'CMP quenches the fluorescence of RNase A? What is the possible mechanism by which either 2'-CMP or 5'-CMP stabilizes RNase A against urea-induced unfolding? Since phosphate ions can quench the fluorescence of RNase A (58), it would be useful to know whether the nucleoside or the cytidine ring contributes to the quenching. The binding sites for 2'-CMP and 5'-CMP on RNase A are somewhat different. Our results do not clearly show which functional group in the respective inhibitors plays the main role in the stabilization of RNase A. Since Nelson and Hummel have already examined the stabilization of RNase $A$ against urea-induced unfolding by phosphate ions 
(36), our future studies should focus on the effect of cytosine or cytidine on urea-induced unfolding of RNase A. Further, Kasumov et al. (76) found that the pathways of unfolding of RNase $\mathrm{A}$ in urea and $\mathrm{GdnCl}$ are different at low concentrations of these denaturants, and Liu and Tsou's results (45) also show that the effect of $\mathrm{GdnCl}$ on RNase $\mathrm{A}$ is somehow different from that of urea. Future studies should also involve the examination of the effect of 2'-CMP on GdnCl-induced unfolding of RNase A. Another interesting project involves the determination of the binding constant and the number of binding sites for 5'CMP. This requires the extension of the 5'-CMP saturation profile to higher concentrations by using a more sensitive spectrophotometer. Finally, it would also be useful to know if inhibitor-induced stabilization occurs with other proteins. 


\section{REFERENCES}

1. Stryer, L. Biochemistry , 4th ed.; W. H. Freeman: New York, 1995; Chapter 1, 2,7 , and 16.

2. Walsh, C. Enzymetic Reaction Mechanisms; W. H. Freeman: New York, 1979; p 199 and p 203.

3. Matthews, C. and van Holde, K. Biochemistry; Benjamin/Cummings: Redwood city, CA, 1990; p 187.

4. Ferdinand, W. The Enzyme Molecule; John Wiley \& Sons: New York, 1976; p 131 and $\mathrm{p} 135$.

5. Ptitsyn, O. B. J. Prot. Chem. 1987, 6, 273-293.

6. Blum, A.; Baldwin, R. L. J. Mol. Biol. 1978, 118, 305-316.

7. Schmid, F. X.; Baldwin, R. L. J. Mol. Biol. 1979, 135, 199-215.

8. Biringer, R. G.; Fink, A. L. Biochemistry 1982, 21, 4748-4755.

9. Biringer, R. G.; Fink, A. L. Biochemistry 1988, 27, 301-311.

10. Bringer, R. G.; Austin, C. M.; Fink, A. L. Biochemistry 1988, 27, 311-315.

11. Biringer, R. G.; Fink, A. L. Biochemistry 1988, 27, 315-325.

12. Schmid, F. X.; Blaschek, H. Eur. J. Biochem. 1981, 114, 111-117.

13. Creighton, T. E. Prog. Biophys. Molec. Biol. 1978, 33, 231-297.

14. Creighton, T. E. Proc. Natl. Acad. Sci. USA 1988, 85, 5082-5086.

15. Beasty, A. M.; Matthews, C. R. Biochemistry 1985, 24, 3547-3553.

16. Ikeguchi, M.; Kuwajima, K.; Mitani, M.; Sugai, S. Biochemistry 1986, 25, 6965-6972.

17. Goto, Y.; Fink, A. L Biochemistry 1989, 28, $945-952$.

18. Baldwin, R. L. Ann. Rev. Biochem. 1975, 44, 453-475.

19. Kim, P. S.; Baldwin, R. L. Ann. Rev. Biochem. 1982, 51, 459-489.

20. Baldwin, R. L; Creighton, T. E. in Protein Folding, Jaenicke, R., Ed.; Elsevier: 
Amsterdam, 1980; pp 217-260.

21. Baldwin, R. L. Methods in Enzymology, Academic: Orlando, 1986; Vol. 131, section 1 .

22. Kuwajima, K.; Schmid, F. X. Adv. Biophys. 1984, 18, 43-74.

23. Kuwajima, K. Proteins: Struct. Funct. Genet. 1989, 6, 87-103.

24. Creighton, T. E.; Schmid, F. X.; Ptitsyn, O. B.; Goldenberg, D. P.; Freedman, R. B. Protein Folding; W. H. Freeman: New York, 1992; pp 301-351, pp 197-241, pp 243-300, pp 353-403, pp 455-539.

25. Westmoreland, D. G.; Matthews, C. R. Proc. Natl. Acad. Sci. U. S. A. 1973, 70, 914-918.

26. Benz, F. W.; Roberts, G. C. K. J. Mol. Biol. 1975, 91, 345-365.

27. Benz, F. W.; Roberts, G. C. K. J. Mol. Biol. 1975, 91, 367-387.

28. Howarth, O. W. Biochim. Biophys. Acta. 1979, 576, 163-175.

29. Biringer, R. G.; Fink, A. L. J. Mol. Biol. 1982, 160, 87-116.

30. Chignell, D. A.; Azhir, A.; Gratzer, W. B. Eur. J. Biochem. 1972, 26, 37-42.

31. Robson, B.; Pain, R. H. Biochem. J. 1976, 155, 331-344.

32. Tiktopulo, E. I.; Privalov, P. L. FEBS Lett. 1978, 91, 57-58.

33. Barrick, D.; Hughson, F. M.; Baldwin, R. L J. Mol. Biol. 1994, 237, 588-601.

34. Fink, A. L.; Calciano, L. J.; Goto, Y.; Kurotsu, T.; Palleros, D. R. Biochemistry $1994,33,1250412511$.

35. Dill, K. A. Biochemistry 1990, 29, 7133-7155.

36. Nelson, C. A.; Hummel, J. P.; Swenson, C. A.; Friedman, L. J. Biol. Chem. 1962, $237,1575-1580$.

37. Singer, S. J. Adv. Prot. Chem. 1962, 17, 1-68.

38. Brandts, J. F.; Hunt, L. J. Amer. Chem. Soc. 1967, 89, 4826-4838.

39. Jacobson, A. L; Turner, C. L. Biochemistry 1980, 19, 4534-4538.

40. Ginsburg, A.; Carroll, W. R. Biochemistry 1965, 4, 2159-2174. 
41. Ettinger, M. J.; Hirs, C. H. W. Biochemistry 1968, 7, 3374-3380.

42. Nelson, C. A.; Hummel, J. P. J. Biol. Chem. 1962, 237, 1567-1574.

43. Barnard, E. A. J. Mol. Biol. 1964, 10, 235-262.

44. Barnard, E. A. J. Mol. Biol. 1964, 10, 263-281.

45. Liu, W.; Tsou, C.-L. Biochim. Biophys. Acta 1987, 916, 455-464.

46. Makhatadze, G. I.; Privalov, P. L. J. Mol. Biol. 1992, 226, 491-505.

47. Pace, C. N. CRC. Crit. Rev. Biochem. 1975, 3, 1-43.

48. Pace, C. N. Methods in Enzymology 1986, 131, 266-280.

49. Tanford, C. Adv. Prot. Chem. 1970, 24, 1-95.

50. Shellman, J. A. Biopolymers 1978, 17, 1305-1322.

51. Santoro, M. M.; Bolen, D. W. Biochemistry 1988, 27, 8063-8068.

52. Knapp, J. A.; Pace, C. N. Biochemistry 1974, 13, 1289-1294.

53. Pace, C. N.; Marshall, H. F., Jr. Arch. Biochem. Biophys. 1980, 199, 270-276.

54. Shortle, D.; Meeker, A. K. Proteins: Struct. Funct. Genet. 1986, 1, 81-89.

55. Gekko, K.; Ito, H. J. Biochem. 1990, 107, 572-577.

56. Pace, C. N.; Laurents, D. V.; Thomson, J. A. Biochemistry 1990, 29, 2564 2572.

57. Edelhoch, H. Biochemistry 1967, 6, 1948-1954.

58. Chen, R. F.; Cohen, P. F. Arch. of Biochem. Biophys. 1966, 114, 514522.

59. Stryer, L. J. Mol. Biol. 1965, 13, 482-495.

60. Parker, C. A. Photoluminescence of Solutions; Elsevier: Amsterdam,1968; pp $220-229$.

61. Barnard, E. A.; Ramel, A. Nature 1962, 195, 243-246.

62. Deavin, A.; Mathias, A. P.; Rabin, B. R. Biochem. J. 1966, 101(1), 14C-16C.

63. Cathou, R. E.; Hammes, G. G. J. Am. Chem. Soc. 1964, 86, 3240-3245.

64. Fasella, P.; Hammes, G. G.; Schimmel, P. R. Biochim. Biophys. Acta 1965, $103,708-710$. 
65. Anderson, D. G.; Hammes, G. G.; Walz, F. G., Jr. Biochemistry 1968, 7, 16371644.

66. Flogel, M.; Albert, A.; Biltonen, R. Biochemistry 1975, 14, 2616-2621.

67. Taylor, H. C.; Chaiken, I. M. J. Biol. Chem. 1977, 252, 6991-6994.

68. Richards, F. M.; Wyckoff, H. W. in The Enzymes, 3rd ed.; Boyer, P. D., Ed.; Academic: New York, 1971; Vol. IV, p 760 and p 762.

69. Heinemann, U.; Saenger, W. Nature 1982, 299, 27-31.

70. Borkakoti, N. Eur. J. Biochem. 1983, 132, 89-94.

71. Aguilar, C. F.; Thomas, P. J.; Moss, D. S.; Mills, A.; Palmer, R. A. Biochim. Biophys. Acta 1991, 1118, 6-20.

72. Aguilar, C. F.; Thomas, P. J.; Mills, A.; Moss, D. S.; Palmer, R. A. J. Mol. Biol. $1992,224,265-267$.

73. Heydenreich, A.; Koellner, G.; Choe, H-W.; Cordes, F.; Kisker, C.; Schindelin, H.; Adamiak, R.; Hahn, U.; Saenger, W. Eur. J. Biochem. 1993, 218, 1005-1012.

74. Zegers, I.; Haikal, A. F.; Palmer, R.; Wyns, L. J. Biol. Chem. 1994, 269, $127-$ 133.

75. Zegers, I.; Maes, D.; Dao-Thi, M.; Poortmans, F.; Palmer, R.; Wyns, L Prot. Sci. 1994, 3, 2322-2339.

76. Kasumov, E. A.; Volynskaya, A. V.; Shishkov, A. V.; Goldanskii, V. I.; Timiriazev, K. A. Studia Biophysica 1990, 136, 167-170.

77. Nall, B. T.; Baldwin, R. L. Biochemistry 1977, 16, 3572-3576.

78. Markus, G.; Barnard, E. A.; Castellani, B. A.; Saunders, D. J. Biol. Chem. 1968, 243, 4070-4076.

79. Nonnenmacher, G.; Viala, E.; Thiery, J. M.; Calvet, P. Eur. J. Biochem. 1971, 21, 393-399. 
Irving Gees

20 June 1995

4700 Broadway Apt. 4B

New York, NY 10040

Dear Sir:

I am a graduate student in the Chemistry Department at San Jose State University. I would like to use Figure 6-14B in "Biochemistry", ISBN: 0-8053-5015-2, written by Matthews and van Holden, in my thesis. The publishers have told me that you hold the copyright to this figure. I write to request permission to allow me to use it in my thesis. Three copies of the thesis will be published. Graduate Studies requires written permission for use of published figures in theses prior to their publication. I can be reached by FAX c/o Dr. R. G. Biringer 408-924-4945 or at the address given below.

I am looking forward to hearing from you and thank you for considering this request.

Ms. Fang Li

555 South Tenth St. \#10

San Jose, CA 95112

Sincerely,

junglier

Fang tiu You have nu l permussum to use

my figure 6-146 of Ribonuclease -S. on page 187 of

BiDCitemisting ty Mathews and van Hold.

Please credit me for the use of this illustration. there is no fee for This usage.

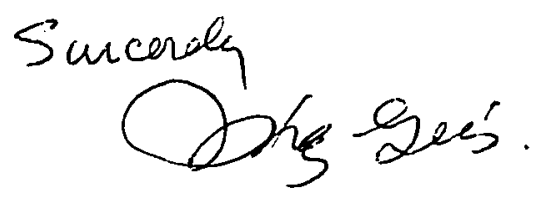


John wiley and Sons Wiley Drive

Somerset, N OBaT5-1272

FAN: 212-850-6008
12 JUN per:

Dats: May 30, 1995
Dear John Wriley and Sons Representotive:

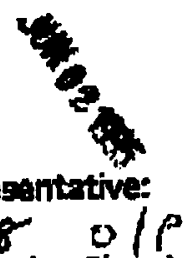

ISEN OHF

I am a graduate sudient in the Chemistry Departmant at San Jose

State Untwersty. I would like to use Figune 41,44 in "The Enzyme

Moldeule", ISBNiorm write to request permlesion to allow me to use them in my thesis. Three coplas of the thesis will be published. Graduato Studies requires written permission for use of putblistred figures in theses prior to their pubfication. I can be reached by FAX c/0 Dr. R. G. Biringer 408-924-4945.

I an looking forward to hearing from you and thank you for considenting this request.

Sincerely.

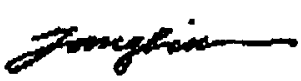

Fang Liu

Som colity isors, Ltd
Hoglte tu this mational

poperoliod by

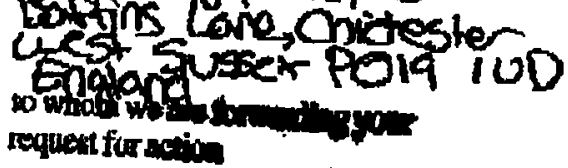

requet for action

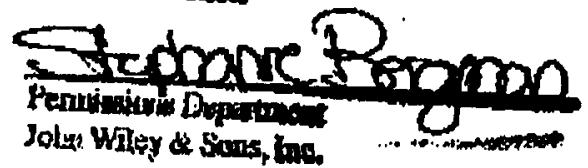

Permlagion granted,

Proper credit muth be ghen to our publicenlon

Provers Saspofosed 12/7/95

Formlagions Department

For John Whity a Sons Lid.

It malorlal appears in ourwork wtth evectr to inpther source, autnotization Irom thal coures lï requirea.
Credit should Include the following components: Titlo, author(s) and/or editor(3), Copyright ( ) (date and owner). Reprinted by permission of John Wiley a Sons. Ltd. 
John Wiley and Sons

Wiley Drive

Somerset, NJ 08875-1272

FAX: 212-850-6008

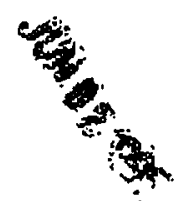

Date: May 30, 1995

Dear John Wiley and Sons Representative:

ISBN 0.47DL8228

I am a graduare student in the Chemlstry Department at San Jose State Unlversity. I would like to use Figure 41,44 in "The Enzyme Molecule", ISBNetraforititen by W. Fordinand, in my thesis. I write to request permission to allow me to use them in my thesis. Three copies of the thesis will be publistred. Graduate Studies requires written permission for use of published figures in theses prior to their publication. I can be reached by FAX c/O Dr. R. G. Biringer 408-924-4945.

I am looking forward to hearing from you and thank you for considering this request.

Sincerely,

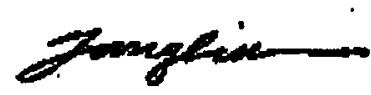

Fang Liu

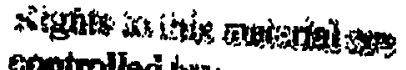
epotonled by bonfins

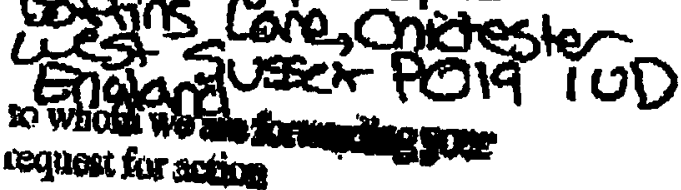
request for actios
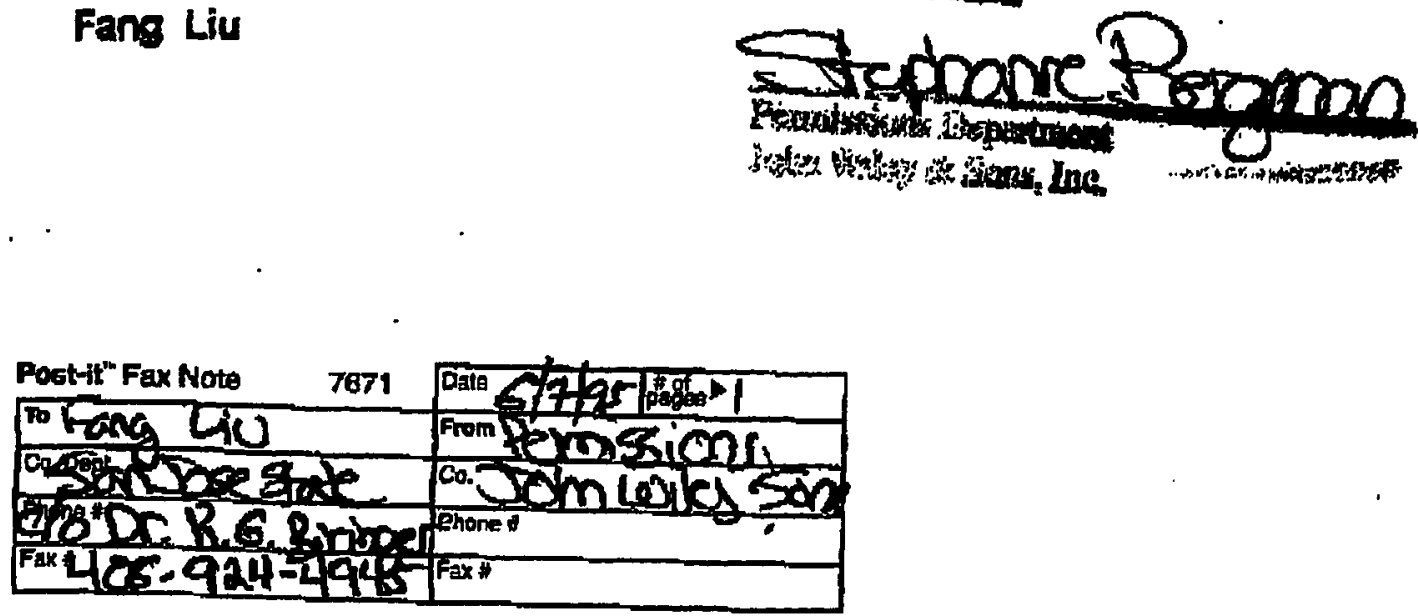
Plenum Publishing Corporation

233 Spring St.

New York, NY 10013-1578

FAX\#: 212-463-0742

Date: May 30, 1995

Dear Plenum Publishing Corporation Representative:

I am a graduate student in the Chemistry Department at San Jose State University. I would like to use Figure 1 in "Journal of Protein Chemistry", (1987), Vol. 6, \#4, p.274, written by Oleg B. Ptitsyn, in my thesis. I write to request permission to allow me to use it in my thesis. Three copies of the thesls will be published. Graduate Studies requires written permission for use of published figures in theses prior to their publication. I can be reached by FAX c/O Dr. R. G. Biringer 408-92A-4945.

I am looking forward to hearing from you and thank you for considering this request.

Sincerely,

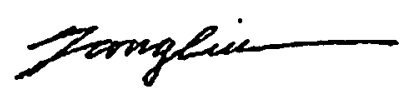

Fang Liu

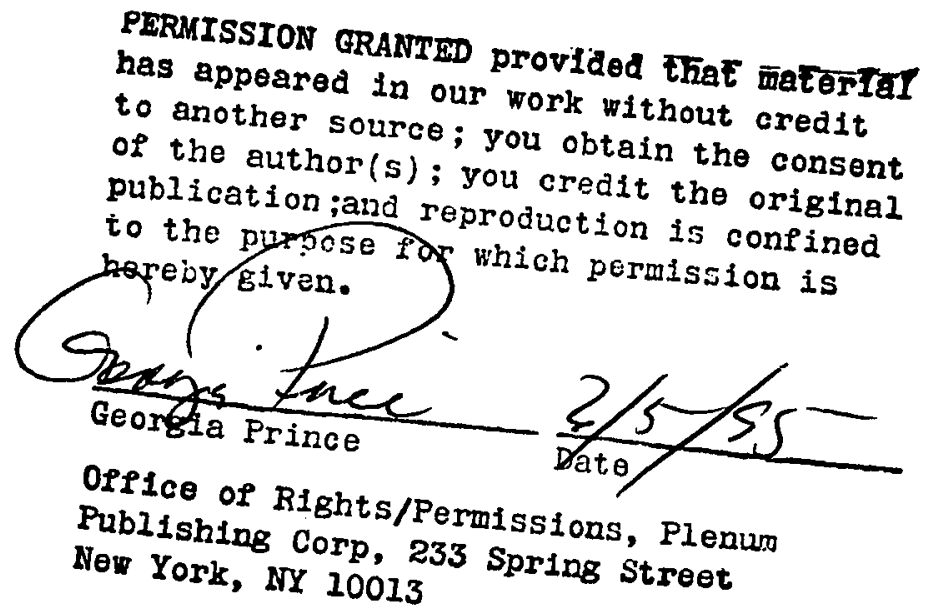

OPflce of Rights/Permissions, Plenum
Publishing Corp, 233 Spring Street
Now York, NY 10013 


\title{
W.H. FREEMAN AND COMPANY SCIENTIFIC AMERICAN BOOKS COMPUTER SCIENCE PRESS
}

\author{
41 MADISON AVENUE, NEW YORK, NEW YORK 10010 \\ TELEPHONE: (212) 576-9400
}

FAX: (212) 689-2383

\section{AGREEMENT FOR PERMISSION TO REPRINT}

To: Fang Liu

From: Katherine Loughran

Date: 8 June 1995

THIS FORM MUST BE SIGNED AND ALL COPIES RETURNED TO THE PERMISSIONS DEPARTMENT. THIS PERMISSION IS NOT VALID UNLESS IT IS SIGNED BY BOTH PARTIES.

The undersigned requests a non-exclusive license to reprint the following selection(s):

TITLE: BIOCHEMISTRY 4/E

Figures 2-31c, and 2-36

AUTHOR: Stryer

To be used in: the thesis of by Fang Liu

Address: San Jose State Univ, Dept of Chem, One Washington Square, San Jose, CA 95192-0101

To be published by:

Hardcover/Paperback

Text/Trade/Other

Probable retail price:

The undersigned agrees as follows:

1) Full credit in every copy printed, on the copyright page or in the caption, or as a footnote on the page on which the quotation/illustration appears, or if in a magazine or journal, on the first page of each quotation/illustration covered by the permission or scrolled at the end of the program, videodisc or CD-ROM exactly as follows:

From: BIOCHEMISTRY 4/E by Stryer. Copyright (c) 1995 by Lubert Stryer. Used with permission of W.H. Freeman and Company. 2) To pay on publifation of the work, or within 24 months of the date of granting the permission, whichever is earlier, a fee of:
No Fee

3) Payment must be accompanied by one copy of the licensing agreement and one copy of the published work to ATTN: PERMISSIONS DEPARTMENT, W.H. Freeman and Company.

4) The permission granted applies only to the edition of the work specified in this agreement and is not transferable.

5) This license is valid for a period of seven years from the date of publication of the work named herein.

6) This permission applies, unless otherwise stated, solely to the publication of the above-cited work in the English language throughout the world

7) This permission does not extend to any copyrighted material from other sources which may be incorporated in the works in question nor to any illustrations or charts, unless otherwise specified.

8) This selection may be reproduced in Braille, large type, and sound recordings provided no charge is made to the visually handicapped

9) This agreement must be retumed within 120 days from the date above or the permission shall automatically terminate.

Date: Tune 15, 1995

Date:

June 21, 1995
Signature of Applicant:

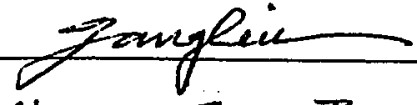

Dept. of Chem., San Tose state University Address:_One Wasbingtón Square, Sum Tose, CA g 5192

Permission on the foregoing terms W.H. FREEMAN AND COMPANY

By_ Nancy Walker Permissions Department 
Marcel Dekter, inc.

270 Modiog Ave

6 June 1995

New York, Ny 10016

FAX $914-796-1772$

Dear Marcel| Dekker, mc. Representitive:

I am gradunte student in the Chemistry Department at San Jose

State University. I would He to use the Figure for the cytidine-3x-

Structure and function", (1976), p. 367, chit of RNase A in "Enzyme

by vour combans in my thocic. to use it in my thesis. Three copies of the thes farmisson ro allow me Graduste Staplies requires mitten permion thesis wit be publushed.

In theses priar to that publication. Biringer toas $924-4945$.

I am lopking forward to hearing from you and thank you for considering this request.

Sincerely,<smiles>CC=CC(=O)[C@H]1C=C[C@@H]1C</smiles>

Fang Liu
Fetimssion CRanmed with the onderstending thet proper credit be given to Marced Dekther linc. Peterence Led should inclede:

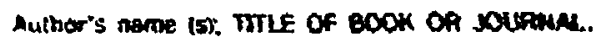

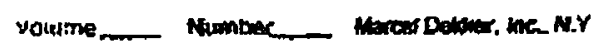

Yea- at Pubincotuon

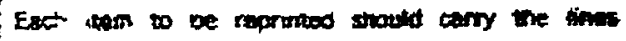

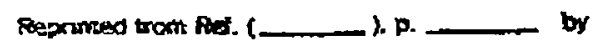

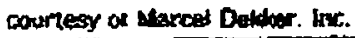

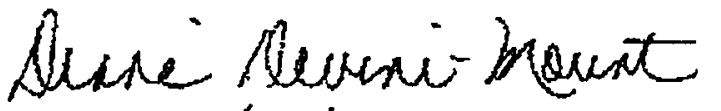

$$
\begin{aligned}
& 7 / 17 / 95
\end{aligned}
$$

